\title{
El soft law en derecho administrativo y su control judicial en Colombia
}

\author{
DARÍO MARTíneZ JURAdO ${ }^{1}$
}

\section{RESUMEN}

El soft law administrativo o el uso del derecho blando es una realidad en la práctica de la Administración que facilita el logro de los fines del Estado posmoderno. Sin embargo, también es factible que en esa zona de producción normativa abundante se soslayen principios, garantías fundamentales y derechos de los destinatarios de las normas o terceros interesados. Este documento muestra la necesidad de que estos instrumentos estén alineados al principio de juricidad, ya que su procedimiento de emisión es informal y, en la escena jurídica, se les considera como carentes de efectos obligatorios $y$, por ende, de control judicial.

Palabras clave: Administración corporativa, Buena administración, Eficacia y eficiencia administrativa, Sistema de pesos y contrapesos, Control de actos administrativos informales, Garantías del debido proceso.

1 Abogado de la Universidad Cooperativa de Colombia. Especialista en Derecho Administrativo de la Pontificia Universidad Javeriana, en Derecho Constitucional de la Universidad Nacional de Colombia, en Derecho Procesal, Contractual y Laboral de la Universidad del Rosario. Magíster en Derecho Administrativo de la Universidad Externado de Colombia, Bogotá, Colombia. Asesor jurídico del Tribunal Administrativo del Quindío, Popayán, Colombia. Correo-e: dariomj9@hotmail.com. Fecha de recepción: 20 de enero de 2018. Fecha de modificación: 20 de marzo de 2018. Fecha de aceptación: 10 de mayo de 2018. Para citar el artículo: MarTíneZ JuRADO, Darío, "El soft law administrativo y su control judicial en Colombia", Revista digital de Derecho Administrativo, Universidad Externado de Colombia, n. ${ }^{\circ} 20,2018$, pp. 289-343. DOI: https://doi.org/10.18601/21452946.n20.12. 


\title{
The Soft Law in Administrative Law and its Judicial Review in Colombia
}

\begin{abstract}
Administrative soft law is a reality in the Administration's activity which facilitates the achievement of effective and efficient results. However, this abundant informal normative production can ignore principles and fundamental rights of individuals. This document shows the need for soft law instruments to be aligned with the principle of rule of law and judicial review since their issuing procedures are not regulated, and despite the fact that the acts containing these informal rules are devoid of mandatory effects.
\end{abstract}

Keywords: Corporate Administration, Good Administration, Administrative Efficacy and Efficiency, Checks and Balances, Judicial Review, Due Process.

\section{INTRODUCCIÓN}

El constitucionalismo busca un equilibrio -un equilibrio siempre inestable y siempre difícil-entre el ejercicio del poder [...] y el control del poder.

Giovanni Sartori, Elementos de teoría política

El derecho administrativo colombiano se encuentra en un proceso de actualización debido al impacto que trajo su constitucionalización, el control de convencionalidad y la proliferación de fenómenos sociales, económicos y culturales propios de la globalización. Aquellos aspectos han derivado en que la Administración asuma un rol protagónico en la solución de problemáticas coyunturales y urgentes que afectan las sociedades contemporáneas, dado que esta tiene como tareas principales las de regular todas aquellas actividades de orden político, estipular criterios para una economía social de mercado, procurar por un ambiente sano y el desarrollo sostenible, así como promover equidad y justicia social. Simultáneamente, en el marco constitucional del Estado social y democrático de derecho y la Ley 1437 de 2011, las autoridades administrativas asumieron el papel de garantes principales de los derechos de los coasociados, bajo la supervisión de un juez contencioso administrativo dotado de notables poderes (cautelares y definitivos).

En ese escenario, la nueva gobernanza, como concepto adoptado de compromisos internacionales con organismos multilaterales, impregnó la mayoría de Estados democráticos del mundo, incluido por supuesto el colombiano, y promueve en las administraciones modernas actuaciones oportunas, coherentes, eficaces e integrales, pero fundamentalmente flexibles, participativas y concertadas a efectos de obtener los resultados que la sociedad espera y las 
normas superiores exigen. Este horizonte por el cual atraviesa la Administración colombiana moderna se muestra impulsada por un escenario en donde la producción jurídica del legislador y la rama judicial se encuentran paulatinamente en crisis debido a diversos factores, algunos propios de la dinámica legislativa y el rol del juez.

El soft law administrativo involucra un conjunto de instrumentos jurídicos que procuran que la Administración alcance y materialice eficientemente los fines y valores estatales, sus objetivos políticos y las obligaciones internacionales. Es una realidad de la práctica jurídica de la Administración que no ha sido ampliamente estudiada en la escena académica colombiana, pero sin duda se internó gradualmente en el derecho administrativo moderno para quedarse.

En tal virtud, el trabajo parte de la base de reconocer una realidad jurídica rampante que ha invadido las actuaciones de la Administración pública posmoderna, esto es la utilización de herramientas de derecho blando, pero que el derecho administrativo colombiano tradicional no le ha prestado la atención que se merece, ya que generalmente analiza las implicaciones del típico "acto administrativo" con las características reiteradas por la doctrina "manifestaciones de la voluntad de carácter unilateral, creadoras de situaciones jurídicas, pueden ser de dos clases: generales o individuales"2. Ello genera la falta de análisis de otros instrumentos con connotaciones y principios diferentes, que también cobija el derecho administrativo, pero que por su naturaleza específica no encuadran perfectamente en la mencionada definición. En ese orden de ideas, en Colombia, al soft law administrativo lo encontramos en resoluciones, circulares, directrices, circulares de servicio, instrucciones, códigos de conducta, protocolos, normas técnicas, guías ambientales, cupos negociables de emisión, acuerdos informales y la información al público, entre otros. Es decir, una serie de herramientas jurídicas que teóricamente no constituyen normas obligatorias o actos administrativos con las características que la doctrina tradicional ha concebido, pero sin duda producen efectos jurídicos verificables.

Este documento se encargará de despejar el siguiente interrogante: ¿Es adecuado que dentro del Estado social de derecho colombiano existan expresiones de la Administración, como son las herramientas de soft law administrativo, sin control judicial por parte de la jurisdicción contenciosa administrativa ni de otra estirpe, debido a que no encajan en la definición tradicional de acto administrativo?

Para dilucidar este tópico controversial, en el primer aparte destacaremos como el concepto de Estado posmoderno y algunos fenómenos sociales,

2 Jaime Orlando Santofimio Gamboa, Tratado de derecho administrativo. Introducción a los conceptos de la administración pública y el derecho administrativo, 3. a edición, Bogotá: Universidad Externado de Colombia, 2003, p. 440. 
económicos, políticos y culturales característicos de la época en que vivimos, propiciaron el uso frecuente de mecanismos de soft law administrativo en las relaciones entre los particulares y la Administración. Describiremos una aproximación conceptual del soft law administrativo, teniendo como referencia autores que recientemente se han encargado de analizar su incorporación y repercusiones dentro del orden jurídico. Seguidamente, en el siguiente aparte identificaremos la presencia y utilización de estos mecanismos en la escena jurídica colombiana. Para el efecto, enunciaremos algunos ejemplos que evidencian su existencia y que por su contenido e impacto sobre los derechos de los coasociados, denotan su importancia jurídica. Por consiguiente, se referirán algunas peculiaridades de estos mecanismos para llamar la atención de la presencia de controles adecuados sobre estos instrumentos, por medio de los cuales se eviten excesos en el ejercicio de este poder particular del Estado. Por último, en la tercera parte evocaremos los fundamentos teóricos, constitucionales y legales que apartan cualquier posibilidad de que manifestaciones del poder del Estado carezcan de control o se ubiquen en zonas penumbra o inmunidad, debido al peligro que ello representaría para ciertas garantías propias del Estado social de derecho, y la preexistencia del juez contencioso administrativo en el diseño constitucional colombiano, que está situado en el orden jurídico como freno y contrapeso a expresiones del poder de la Administración. Por lo tanto, se razonará sobre la necesidad de implementar sin ambages controles a estas novedosas expresiones de la Administración.

\section{LA IRRUPCIÓN DEL SOFT LAW ADMINISTRATIVO EN EL MARCO DEL ESTADO POSMODERNO}

\subsection{El paso hacia el Estado POSMOderno \\ Y LA ADMINISTRACIÓN CORPORATIVA}

El derecho administrativo tradicionalmente se cimentó sobre la base de relaciones de sujeción, esto es, aquellas en las cuales al individuo se lo concibe como sujeto que debe obedecer las órdenes que la Administración dicta respecto de las cuales no tiene ningún tipo de injerencia; una relación esencialmente de sometimiento, propia del poder de policía que caracterizó al Estado liberal. Con el tránsito hacia el Estado benefactor o prestacional en la que el "administrado" era beneficiario de algunas prestaciones y usuario de servicios públicos, se gestó una relación administrativa mucho más cívica y activa debido a la presencia de una interacción constante entre los particulares y el Estado en la búsqueda de mayores y mejores prestaciones. Posteriormente, como reacción a la barbarie humana padecida en la Segunda Guerra Mundial, irrumpe el Estado constitucional. Este modelo coincide con la Declaración de los Derechos del Hombre de las Naciones Unidas (1948) y la Constitución de Bonn 
(Alemania, 1949), y su énfasis radica en la materialización de los derechos fundamentales del ser humano; ello constituye su consigna principal, que impregnó el orden jurídico universal, no sujeta a los vaivenes de las mayorías. En el referido proceso emergieron las teorías neoconstitucionalistas ${ }^{3}$, con las cuales se intensificó la necesidad de que las cartas políticas de los Estados democráticos no se restrinjan a establecer competencias y separar los poderes públicos; bajo sus lineamientos deben instituirse verdaderos mandatos sustantivos que condicionen la actividad estatal por medio de la ordenación de valores, principios, fines y objetivos, comprometidos con la protección eficiente de la dignidad del ser humano.

Por ende, en este nuevo marco, todas la áreas del derecho se muestran irradiadas por las normas superiores. Para el derecho administrativo significó una mejora en la posición del ciudadano, puesto que el derecho constitucional garantiza que las personas sean escuchadas e involucradas por las autoridades públicas en todas las materias que los afectan. Los derechos fundamentales son invocados con frecuencia y naturalidad. Con ello se corrige el rigorismo del derecho ordinario, que en ciertas ocasiones se aleja de la protección de los ciudadanos. En el Estado constitucional, la norma superior cohesiona todo el derecho, bajo un solo sistema jurídico coherente, que renueva la dogmática del derecho administrativo y fuerza reflexiones sobre su construcción sistemática ${ }^{4}$. En efecto, el particular no solo constituye usuario y sujeto pasivo de algunas actuaciones y prestaciones de la Administración, sino pieza cardinal y razón propia de la acción estatal. Nuestro Estado adhirió al concepto de Estado social de derecho; según el jurista y politólogo alemán Hermann Heller ${ }^{5}$, tal condición implica la consolidación de la igualdad en un sentido material, que abarca la totalidad de la "cuestión social", y no se agota en una simple igualdad formal. La igualdad material supone reconocer derechos y para la administración, adoptar decisiones con incidencia directa en la vida social de los ciudadanos, más allá del ámbito estricto del individualismo y de los simples derechos subjetivos. La conquista progresiva de los derechos sociales es el elemento finalístico de esta estructura. Por ende, la administración debe fortalecer la seguridad jurídica, las garantías, la participación y la transparencia en todas sus actuaciones.

La Administración en la posmodernidad se apertura, entonces, hacía nuevas formas de colaboración y participación con los particulares; dentro de un

3 Los principales representantes de esta corriente doctrinaria son: Ronald Dworkin (Freedom's Law), Robert Alexy (El concepto y la validez del derecho) y Gustavo Zagreblesky (El derecho dúctil), entre otros.

4 EberhaRd SCHMidt-Assmann, La teoría general del derecho administrativo como sistema, Madrid: Marcial Pons Ediciones, 2003. p. 3.

5 Hermann Heller, Escritos políticos, Madrid: Alianza Editorial, 1985. 
Estado posmoderno ${ }^{6}$ se convierte en un gestor del bien común, de los derechos constitucionales y de la eficiencia en la prestación de los servicios públicos, a lo que podemos denominar un verdadera "administración corporativa" ${ }^{17}$, en la cual se desvanecen los vestigios de la predominante relación vertical que caracterizó históricamente a las actuaciones de las autoridades públicas. Se trata de comprender el principio de juricidad ${ }^{8}$ como un concepto integral. Con ello se propone una gestión administrativa de calidad, que procure la erradicación de la corrupción bajo la adopción de estándares democráticos, de manera que emergen deberes de motivación de los actos, publicidad, transparencia, rendición de cuentas, objetividad y tecnicidad en la regulación, cartas de calidad de los servicios públicos, códigos de ética y mérito en el acceso a los cargos de la Administración, entre otros. Es decir, los campos de discrecionalidad con las que cuenta válidamente la Administración no deben ser arbitrariedad sino precisamente colmados con los lineamientos de una buena administración,

6 Sobre el punto, el profesor Chevallier precisa: "la nueva configuración del Estado, que se perfila obviamente con bastantes alternativas, desfases y distorsiones, lleva a preguntarse sobre las condiciones de ejercicio del poder estatal en las sociedades inscritas en la posmodernidad: comportando vínculos complejos de interdependencia, expuesto a la competencia de múltiples poderes con los cuales debe conciliar, atravesando por numerosas líneas de fractura, el Estado parece haber perdido buena parte de sus medios de acción y su capacidad de influencia sobre la evolución social; ante unos ciudadanos exigentes y reivindicativos, que no se dan por satisfechos ya con el principio de delegación inherente al sistema representativo sino que se proponen tener derecho de fiscalización sobre las políticas públicas, debe negociar permanentemente con los distintos intereses sociales. Las sociedades posmodernas se confrontan así con un problema de "gobernabilidad", que requiere nuevos métodos, diferentes de las técnicas de gobierno". JACQuES CHEVALLIER, El Estado posmoderno, Bogotá: Universidad Externado de Colombia, 2014, p. 403.

7 En su cátedra, el experto mexicano Aguilar expuso: "El sector público debe tomar en serio y adecuar a su misión la posición pionera que tuvo el sector privado en el campo del gobierno corporativo, que elaboró y acordó desde años atrás Principios y Códigos de Gobierno o Gobernanza Corporativa, que establecieron normas de comportamiento de los altos directivos e instituyeron instancias colegiadas de dirección (Juntas de Gobierno, Consejos Directivos o de Administración), cuyos miembros deben ser independientes, representativos de propietarios de la empresa e interesados en su desempeño y de probada solvencia técnica y moral, con el fin de mejorar, validar, controlar y transparentar el proceso decisional de los altos ejecutivos [...] de esta manera anticipar errores decisionales que acarrean daños a los propietarios, miembros, proveedores, clientes de la corporación y a los interesados en su desempeño, productos y servicios". LuIs F. AGuILAR, La gobernanza de los asuntos públicos, Centro de Gobernanza Pública y Corporativa Universidad del Turabo, Instituto de Investigación en Política Pública y Gobierno, Universidad de Guadalajara, Cátedra Magistral, 25 de marzo 2014. Disponible en línea http://ut.suagm.edu/sites/default/files/ uploads/Centro-Gobernanza/CATEDRAL_AnUAL/La-Nueva-Gobernanz a-Publica.PR.uT.pdf [consulta el 21 de octubre de 2017].

8 Entendido en nuestro criterio no solo como la sujeción de la actividad estatal a los mandatos constitucionales y convencionales producto de la constitucionalización del derecho administrativo moderno, sino también la orientación de la función administrativa hacia la consecución material de los criterios finalistas que estas normas superiores imponen. 
principio y derecho producto del proceso de la constitucionalización del derecho administrativo.

Este nuevo panorama del derecho administrativo es ilustrado por el profesor español Javier Barnés, quien explica los fenómenos posmodernos que desbordaron los principales pilares en los que tradicionalmente nuestra disciplina había descansado: derecho nacional, derecho del poder y derecho de vocación ejecutiva, los cuales indefectiblemente, como veremos, tienen repercusiones en las formas de actuar de la Administración y su control. Acerca del tema, el mencionado autor expone que llegó a pensarse que la regulación debía ser pública e imperativa, o de lo contrario no era regulación. Hoy se habla de un derecho administrativo global, fruto de la privatización y otros fenómenos, parecía que el Estado iba en retirada, sin embargo, los reclamos sociales, las normas superiores y la racionalidad administrativa requieren corresponsabilidad entre sector público y privado en las tareas regulatorias, lo que exige al derecho administrativo trasladar sus esencias (consultas y participación, transparencia, motivación, representatividad, independencia y objetividad, control y rendición de cuentas a áreas "desreguladas" o "privatizadas") ${ }_{i}$ es decir, el derecho privado incorpora valores y fines públicos ${ }^{9}$.

A lo anterior se suma la fuerza de las normas convencionales y constitucionales (buena fe, igualdad de trato, garantías del debido proceso, democracia participativa u eficacia, moralidad, entre otras) que impregnan intensamente al derecho administrativo y concretamente la función y gestión administrativa, lo cual comporta el derecho de los particulares a participar en las decisiones que los afectan y a generar relaciones con la Administración paulatinamente más horizontales, consensuadas, persuasivas y dinámicas. Todo ello materializa el principio y derecho a la buena administración, introducido implícitamente en el orden jurídico colombiano ${ }^{10}$. En ese orden de ideas, como lo propone el

9 Alberto Montaña Planta, Andrés Ospina Garzón y Javier Barnés Vázquez, "Justificación, retos y aporte al derecho administrativo", en 100 años de la jurisdicción de lo contencioso administrativo. XIV Jornadas de Derecho Administrativo, Bogotá: Universidad Externado de Colombia, 2014, pp. 49-50.

10 Debe anotarse que la reciente jurisprudencia del Consejo de Estado (Sección Tercera, Sub. C, 10 de octubre de 2016, rad.11001-03-26-000-2015-00165-00) ha intentado aproximarse a este concepto del Estado posmoderno, bajo el siguiente entendimiento: "Existe una cláusula de competencia especial para la Administración que deriva de las funciones que le asignó el constituyente en el artículo 209 constitucional, siendo estas: i) Estar al servicio de los intereses generales, por oposición a los partidistas, gremiales u otros que no representen el bien común, ii) Ceñirse a los principios de igualdad, moralidad, eficacia, economía, celeridad, imparcialidad y publicidad $i$, por último, iii) Ejercer estas funciones mediante los instrumentos de la descentralización, la delegación y la desconcentración de ellas. [...] el principio jurídico de la Buena Administración [...] postulado normativo que ordena, en la mayor medida de las posibilidades fácticas y jurídicas, que la Administración garantice los derechos de los administrados cuando entran en interacción con ella, ejecute de buena fe y bajo el estándar de la debida diligencia los deberes funcionales que 
profesor francés Jacques Chevallier en su obra el Estado posmoderno, es un concepto al cual se adscriben países emergentes como Colombia. En virtud de esta tendencia por la cual atraviesan los Estados democráticos, se genera un proceso de transformación del derecho administrativo que conlleva repensar el derecho público y en especial hallar formas más eficientes de administrar ${ }^{11}$. La Administración debe propugnar entonces, por la eficacia y adaptabilidad por encima de la usual rigidez y coerción.

\subsection{El AUGE DE NUEVAS FORMAS DE ACtUACIÓN DEL EstAdo}

El derecho administrativo moderno reconoce fenómenos como el modelo de economía global, el multiculturalismo, la injerencia de los organismos internacionales, las innovaciones tecnológicas, la sociedad de la información, la igualdad de género, la sensibilidad por los derechos constitucionales, los derechos de los animales, el medio ambiente y el concepto del desarrollo sostenible. Estos aspectos determinan procesos sociales, políticos, económicos, culturales y ambientales que indudablemente generan transformaciones en el modelo de Estado y, esencialmente, en la forma de administrar, en razón a la velocidad y diversidad con que las realidades y problemáticas se transforman, al tiempo que el coasociado exige ser escuchado y reclama eficiencia de la actividad gubernamental ${ }^{12}$. Al anterior paradigma que reta a los Estados posmodernos como el colombiano, se suman los siguientes escenarios que impulsan la adopción de nuevos instrumentos jurídicos con el fin de que la Administración logre adaptarse oportunamente a la nueva realidad:

a. La Administración garante. Por virtud de la Carta Política de 1991 y la Ley 1437 de 2011, la Administración se ubica como protagonista en la efectividad de los derechos reconocidos a los coasociados, compelida con intensidad a que en todas sus actuaciones observe principios como la igualdad de trato, imparcialidad, buena fe y responsabilidad. Pero novedosamente, se imponen deberes verificables tendientes a generar espacios de participación y coordinación con los particulares, transparencia de la actividad administrativa y publicidad. Este fenómeno, verbi gratia, lo podemos comprobar en servicios como

el ordenamiento jurídico convencional, constitucional y legal le ha confiado y adopte las decisiones que correspondan de manera razonable y ponderada conforme a los valores, principios y reglas que se desprenden del marco jurídico legal, constitucional y convencional". Cabe agregar que aquellos deberes derivados del principio y derecho de la buena administración son fácilmente deducibles bajo una interpretación sistemática de las normas constitucionales que orientan la función administrativa (arts. 1, 2, 6, 48, 49, 67, 90 y 209, entre otros, y Ley 80 de 1993, art. 40), que suponen además la prestación de los servicios públicos conforme a estándares de eficacia y eficiencia.

11 JaCQues Chevallier, El Estado posmoderno, op. cit., pp. 141-144.

12 Juan-Cruz Alli Aranguren, Derecho administrativo y globalización, Madrid: Editorial Aranzandi, 2004, p. 377. 
salud, seguridad social, educación y cultura, en los cuales la Administración ya no posee su monopolio; sin embargo, está obligada a garantizar su prestación eficiente en todo el territorio nacional (art. 365 C.P.). A la Administración de hoy en día se le exige con seriedad la rendición de cuentas o accountability, conforme al artículo 15 de la Declaración del Hombre y del Ciudadano de 1789, "La sociedad tiene derecho a pedir cuentas a todo agente público de su administración"; ${ }^{\prime}$ el acceso a la información, el control de la sociedad, la transparencia y la capacitación de los agentes estatales. La mora en las respuestas a las peticiones de los ciudadanos y el silencio son comportamientos que tienden a ser desterrados y sancionados en la actividad administrativa moderna.

b. La crisis de la rama legislativa y la pérdida de protagonismo de la Ley. En efecto, el legislador no se adapta ni reacciona adecuada y oportunamente a los cambios y avances tecnológicos de esta época, debido a los propios procedimientos legislativos que obligan a superar varios pasos antes de la adopción de las leyes (reglas de mayorías, número de debates, orden de proyectos legislativos, etc.). Por tanto, el contexto supera la iniciativa legislativa y las leyes existentes. A lo advertido se añade la falta experticia de los representantes del pueblo en cuanto a las problemáticas y especialidades de las ciencias que imperan en la modernidad, cuya complejidad y alto grado de especialización termina por marginar a las instancias políticas de esta clase de debates. En consecuencia, el legislador se ve forzado a generar leyes abiertas e indeterminadas con el objetivo de que sean concretadas por las autoridades estatales "autónomas" o independientes. También es de resaltar la incorporación de normas supranacionales al ordenamiento interno, que deben ser observadas en cualquier campo de decisión, muchas de ellas de carácter especializado y técnico, que no es sencillo su desarrollo integral en una ley ordinaria o instrumento normativo común.

c. La crisis de la rama judicial. En razón al incremento de leyes indeterminadas y a la irrupción de las cláusulas constitucionales en permanente tensión, al igual que el carácter técnico de numerosos debates, se ocasiona la multiplicación de interpretaciones judiciales, muchas veces poco técnicas o acordes a la ciencia a la cual van dirigidas. El escaso presupuesto estatal de la rama judicial e insuficiente apoyo técnico en la labor judicial colombiana petrifica la actuación del juez e impide respuestas coherentes y oportunas a las necesidades de la sociedad moderna.

d. Ante la indeterminación de las leyes, la Administración es el primer actor que se enfrenta a las problemáticas de la sociedad posmoderna. Por consiguiente, a la Administración le corresponde, de acuerdo con el profesor español Daniel Sarmiento ${ }^{13}$, llenar los espacios dejados por el legislador para que sean precisados y actualizados en otras fuentes de derecho. Aun cuando la Ley 1437 de 2011 optó por un 
esquema que resalta la importancia de las decisiones judiciales e impuso a la Administración el deber de tomarlas en cuenta en los diferentes asuntos bajo su responsabilidad, en la práctica ello no siempre resulta posible ni adecuado, dado el tecnicismo y discrecionalidad que caracteriza muchos de los debates a cargo de las autoridades administrativas. Sobre el punto, es de subrayar que el Estado posmoderno interactúa en distintos escenarios de la sociedad donde una respuesta general o particular de la ley no colma las necesidades de seguridad jurídica o eficacia. Se robustece el papel del reglamento. Efectivamente, es indefectible la existencia de espacios en los cuales la Administración tenga la facultad o posibilidad de delimitar o actualizar prontamente soluciones idóneas, teniendo en cuenta los contextos especializados de las materias que se requiere abordar (economía, medio ambiente, telecomunicaciones, cultura, etc. ${ }^{14}$.

La respuesta audaz del derecho administrativo a este panorama ha sido proliferación de normas de derecho blando o el soft law de la Administración, que se caracterizan por sus elementos de persuasión y consenso. El propósito principal de estos mecanismos es el de influir o inducir la conducta de los destinatarios hacia los fines estatales y convencionales.

\subsection{LA NUEVA GOBERNANZA COMO INSUMO DEL SOFT LAW ADMINISTRATIVO}

Ante la necesidad de generar prontas y adecuadas respuestas de la ciencia administrativa a la dinámica social, económica y política expuesta, se acuña en nuestros países democráticos el concepto de "gobernanza", una metodología para generar buenas prácticas gubernamentales. Ella alude a

un nuevo modo de gobierno, de gestión pública y de acción administrativa en un orden neoliberal, en el que se reduce el protagonismo de los poderes públicos, se desdibujan los perfiles que diferencian lo público de lo privado, se reducen las relaciones de jerarquía en beneficio de las de cooperación, se promueven los procedimentales informales y se trata de integrar y comprometer a la sociedad en redes para la toma de decisiones y seguimiento y control de las acciones políticas.

14 Sobre el tema, el profesor colombiano Héctor Santaella Quintero reflexiona y profundiza: "De este modo, de un régimen administrativo, basado en una compresión rígida y unitaria de la vinculación de la Administración a la legalidad, se pasa a un esquema plural y flexible, en el cual el grado de sometimiento a la ley dependerá del tipo de actividad que se desarrolle y de la forma como esta ha sido regulada. [...] debe también considerarse el hecho de que para la Administración pueda cumplir las numerosas tareas que la sociedad le encomienda es necesario revestirla de ciertos atributos como especialización y capacidad de toma de decisiones [...]. Difícilmente podría convenirse en que se trata tan solo del brazo que ejecuta decisiones externas; de un aparato técnico desprovisto de iniciativa y voluntad propias". HéCTOR SANTAELLA, "La sujeción de la Administración a los precedentes judiciales", Contribuciones para el sistema de precedentes jurisprudencial y administrativo, Bogotá: Universidad Externado de Colombia, 2014, pp. 166-167. 
La negociación, el consenso, la flexibilidad y los procedimientos informales son los nuevos medios de acción, junto con la inducción de las técnicas de gestión empresarial, de los contratos por objetivos y las agencias de administraciones independientes ${ }^{15}$.

De acuerdo con estos lineamientos ${ }^{16}$, se busca que el aparato institucional de los Estados democráticos preste la debida atención a las demandas de la ciudadanía y se luche decididamente contra la corrupción bajo la adopción de esquemas de transparencia administrativa -como son los modelos de rendición de cuentas, entre otros- que desarrollen este propósito. Además, se propicie por la equidad de género en las relaciones del Estado con los coasociados y se profundice el respeto por los derechos humanos y de los animales. Igualmente, en garantía de los derechos constitucionales de tercera y cuarta generación, se materialice el concepto de desarrollo sostenible en las ciudades latinoamericanas, con la incorporación del concepto de urbanismo ecológico. La ciencia administrativa moderna ha otorgado relevancia a que antes de la adopción de directrices o determinaciones administrativas, se consideren seria y suficientemente las preocupaciones, conocimientos y voluntades de los destinatarios; es decir, los intereses de los particulares que directa o indirectamente pudiesen verse afectados con alguna directriz estatal enmarcada en este concepto. Por este motivo la concertación y la participación activa de los particulares cristalizan la democracia de los Estados posmodernos y, por ende, se ubican como principios que guían con determinación la actividad administrativa.

\subsection{Aproximación COnCEPtual al SOft LaW ADMinistrativo}

Con el propósito de concretar los lineamientos que involucra el concepto de la nueva gobernanza y el cambio de paradigma del modelo de administrar el Estado, las autoridades recurren al derecho blando o herramientas del soft law administrativo, ya que dada su informalidad, diversidad y versatilidad permite responder de manera ágil, consensuada y técnica a las problemáticas coyunturales de la sociedad. Al tiempo, las autoridades de manera creativa pueden garantizar las exigencias que aquel concepto envuelve - participación, transparencia, concertación y eficiencia en el logro de los derechos constitucionales

16 Según la profesora Erika Castro, "Los conceptos gobernabilidad y gobernanza fueron trasladados a los Estados latinoamericanos como el nuestro, por diversas instituciones y agencias de cooperación internacional (Banco Mundial, Naciones Unidas, Banco Interamericano de Desarrollo, entre otros), los cuales, han procurado que los Estados miembros en su actividad administrativa reflejen la participación de las personas en la toma de decisiones políticas". ERIKA J. Castro Buitrago, "Aproximación al concepto de gobernanza en Colombia y algunos apuntes sobre su importancia en el derecho ambiental", Opinión Jurídica, vol. 10, n. ${ }^{\circ}$ 20, 2011. 
y convencionales-. En efecto, las herramientas de soft law administrativo, de acuerdo con el profesor Daniel Sarmiento, se caracterizan por

Contar con un presupuesto concreto y un consecuente abierto e indeterminado, que reclama la maximización de los objetivos que pretende cumplir [...] el soft law tiene una causa y objetos específicos, pero su finalidad es genérica, en la medida en que su desafectación del sistema oficial de fuentes le impide contar con plenos efectos jurídicos. Por tanto, el soft law es ontológicamente un mandato de optimización, una proposición prescriptiva que pretende ser cumplida pero solo en grado ${ }^{17}$.

Estos mecanismos pueden asumir la estructura de reglas o principios, pero lo determinante es que se emiten con la vocación de persuadir, desprovista de la finalidad de obligar o constreñir que jurídicamente identificaría a un típico acto administrativo o al bard law. En efecto, pese a la informalidad y versatilidad que caracteriza al soft law administrativo para conjurar ciertas problemáticas de la posmodernidad, dentro de esas interacciones entre particulares y administración, intradministrativas (en una misma autoridad) e interadministrativas (entre entidades), indefectiblemente se genera una relación jurídica.

En ese orden de ideas, al aproximarnos a las manifestaciones de soft law administrativo colombiano podemos señalar varios instrumentos que aparecen en la escena jurídica y deben respetar los anteriores lineamientos, como son: recomendaciones, circulares interpretativas, orientaciones, cartas de instrucciones, documentos CONPES, pautas que emite Colombia Compra Eficiente a sus entidades, directrices presidenciales a los negociadores de paz en la $\mathrm{Ha}$ bana (Cuba), guías ambientales, permisos o cupos negociables de emisión, acuerdos informales, etc. Estos instrumentos, si bien aparentemente no tienen la característica jurídica de ser obligatorios, es indudable que repercuten en la escena jurídica dado que se expiden con el propósito de determinar el horizonte de la actividad estatal y de conducta que se espera de los coasociados. Por ende, la reflexión sobre su régimen jurídico y controlabilidad por los jueces de la Administración se impone.

\section{PERSPECTIVAS PRÁCTICAS DEL SOFT LAW EN EL DERECHO ADMINISTRATIVO COLOMBIANO}

\subsection{LAS PRIMERAS APROXIMACIONES AL SOFT LAW EN EL DERECHO ADMINISTRATIVO COLOMBIANO}

En sus orígenes, el derecho blando en Colombia, como en la mayoría de países, ha sido abordado desde la óptica del derecho internacional, entendido como 
una serie de principios y directrices proferidos por organismos multilaterales e incorporados por medio de tratados y compromisos internacionales, que no son vinculantes u obligatorios para el Estado. Sin embargo, sus lineamientos deben ser tenidos en cuenta en las relaciones internacionales y en la actividad interna del Estado colombiano, a efectos de que las decisiones adquieran legitimidad democrática y universal (medio ambiente, desarrollo sostenible y comercio internacional, entre otras materias). Así, con la finalidad de analizar las repercusiones jurídicas de estas herramientas en nuestro ordenamiento, la Corte Constitucional ha sostenido que son identificables porque se caracterizan por "utilizar verbos no imperativos o complementos directos ambiguos dentro de sus estructuras gramaticales ${ }^{\prime \prime 18}$. Esta naturaleza y génesis del soft law adoptada ahora por el derecho administrativo, como veremos, se mantiene. En tal virtud, encontramos que el derecho administrativo colombiano se aproximó a las herramientas del derecho blando, en el momento en que la Administración utilizó las denominadas "circulares de servicio" y también los denominados "documentos CONPES".

En efecto, en primer lugar, las circulares abundan en la actividad administrativa debido al poder instructor que le es implícito al Estado. Originalmente, bajo el supuesto de tener efectos ad intra, es decir, un cúmulo de orientaciones e instrucciones destinadas a la ordenación interna de las entidades públicas. Por medio de las mismas se puede proyectar un criterio o interpretación sobre la forma de ejercer ciertas potestades públicas o entender determinada norma que eventualmente deba ser aplicada. El Consejo de Estado colombiano, por su parte, destacó que las circulares o las cartas de instrucción se caracterizan porque su finalidad es

dar a conocer el pensamiento o concepto del superior jerárquico a sus subalternos, en relación con determinadas materias, o impartir instrucciones a los empleados de las distintas dependencias sobre la mejor manera de cumplir las disposiciones normativas, sin que se contengan decisiones, se está en presencia de simples actos de servicio ${ }^{19}$.

Cabe recordar que nuestro inveterado Decreto 01 de 1984, en su primera parte, determina las actuaciones administrativas que pueden desarrollar las autoridades públicas dentro de su accionar (artículos 2 a 489). No obstante, no contempló regulación alguna relativa a la forma, contenido o alcance que pueden tener las circulares de servicio en el ámbito de las entidades públicas. Pese a ello, en el libro segundo de la norma en cita, relativo al control jurisdiccional de la actividad administrativa, el artículo 84 sí vislumbró la posibilidad de control de legalidad sobre estos instrumentos. Al respecto, dispuso "También puede 
pedirse que se declare la nulidad de las circulares de servicio". Similar referencia se verifica en la Ley 1437 de 2011, actual Código de Procedimiento Administrativo y de lo Contencioso Administrativo (CPACA) en su artículo 137. Efectivamente, podemos detectar que si bien el Decreto 01 de 1984 y el actual CPACA no estipulan expresamente la facultad de las autoridades públicas para instruir sus actividades mediante el mecanismo mencionado, si realizamos un breve recorrido por normas especiales de competencia que distribuyen funciones y competencias de cada organismo del Estado colombiano, evidentemente, se reconoce su existencia y posibilidad de utilización. Igualmente, de las disposiciones de la Ley 489 de 1998 es factible colegirla. Sobre el punto, y sin ánimo de exhaustividad, podemos enunciar los siguientes ejemplos:

a. El Decreto 412 de 2007, por el cual se reestructura la Superintendencia de Notariado y Registro, consagra en su artículo 12.3: "Instruir a los Notarios y Registradores de Instrumentos Públicos, sobre la aplicación de las normas que regulan su actividad".

b. El Procurador General de la Nación, de acuerdo con el numeral 7 del artículo 7 del Decreto 262 de 2000, tiene la potestad de expedir "directivas y circulares que sean necesarios para el funcionamiento de la entidad y para desarrollar las funciones atribuidas por la ley".

c. Los consejos seccionales de la judicatura, en virtud del artículo $101 \mathrm{nu}$ meral 6 de la Ley 270 de 1996, gozan de la función de "Ejercer la vigilancia judicial para que la justicia se administre oportuna y eficazmente, y cuidar del normal desempeño de las labores de funcionarios y empleados de esta Rama" y generalmente materializan el mandato por medio de circulares de servicio.

d. El ministro de Transporte funge como autoridad suprema de tránsito, en el sentido del artículo 1 de la Ley 769 de 2002 y el numeral 2 del artículo 8 del Decreto 2053 de 2003, "posee facultades administrativas para definir, orientar, vigilar e inspeccionar la ejecución de la política nacional de tránsito y consecuentemente establecer los criterios de interpretación legal".

e. Para algunas autoridades públicas de modo general, la habilitación legal para recurrir a este instrumento la podemos deducir del artículo 41 de la Ley 489 de $1998^{[20]}$. Y para los alcaldes de manera especial, en el artículo 93 de la Ley 136 de 1994.

20 "La orientación, control y evaluación general de las actividades de los organismos y entidades administrativas corresponde al Presidente de la República y en su respectivo nivel, a los ministros, los directores de departamento administrativo, los superintendentes, los gobernadores, los alcaldes y los representantes legales de las entidades descentralizadas y sociedades de economía mixta de cualquier nivel administrativo. En el orden nacional, los ministros y directores de departamento administrativo orientan y coordinan el cumplimiento de las funciones a cargo de las superintendencias, las entidades descentralizadas y las sociedades de economía mixta que les estén adscritas o vinculadas o integren el Sector Administrativo correspondiente". 
Como anunciamos, otra aproximación de la Administración colombiana a herramientas de soft law administrativo aconteció hace varios años con la creación del Consejo Nacional de Política Económica y Social (CONPES) por medio de la Ley 19 de 1958. Aquel ente es la máxima autoridad nacional de planeación y se desempeña como organismo asesor del Gobierno nacional en aspectos relacionados con el desarrollo económico y social del país. En tal virtud, coordina y orienta a los organismos encargados de la dirección económica y social en el Gobierno, mediante el estudio y aprobación de documentos sobre el desarrollo de políticas generales, a los que se denominan "documentos CONPES". Su marco jurídico está consagrado en la siguiente normativa: Ley 152 de 1994, Decreto 627 de 1974, Decreto 2132 de 1992, Decreto 2500 de 2005, Decreto 2148 de 2009, Decreto 3517 de 2009 y Decreto 4487 de 2009. Los miembros del CONPES están relacionados en el Decreto 2148 de 2009 (permanentes, no permanentes, invitados y otros asistentes). El CONPES actúa bajo la dirección del presidente de la República y lo componen como miembros permanentes con derecho a voz y voto, el vicepresidente de la República, todos los ministros, el director del Departamento Administrativo de la Presidencia de la República, el director del Departamento Nacional de Planeación y el director del Departamento Administrativo de Ciencia, Tecnología e Innovación (Colciencias) ${ }^{21}$.

El derecho administrativo tradicional colombiano no se ha preocupado por analizar los alcances y naturaleza jurídica que tienen los documentos CONPES, debido a que se los concibe como "simples" mecanismos no vinculantes de dirección y orientación del Estado. Por tanto, convive un vacío doctrinal que precise sus alcances. De acuerdo con las cartillas de instrucción del Gobierno nacional, mediante los documentos CONPES se establecen "lineamientos generales de política y formula programas y proyectos del Gobierno nacional que responden a una situación problemática identificada por uno o varios sectores administrativos, en el ámbito nacional o regional, definiendo responsabilidades y permitiendo hacer seguimiento a las acciones planteadas"22. Por su parte, las guías de elaboración de estos documentos emitidas por el Departamento Nacional de Planeación, precisan que los mismos

materializan las decisiones de política pública aprobadas por el CONPES y en este sentido constituyen una de las principales herramientas para su formulación e implementación. Estos documentos son el resultado de un trabajo coordinado y concertado entre diferentes entidades e instituciones del Gobierno nacional, donde

21 Información oficial del Departamento de Planeación Nacional. Disponible en línea https:// www.dnp.gov.co/CONPES/Paginas/conpes.aspx [consultado el 16 de agosto de 2017].

22 Información oficial de la Unidad Administrativa Especial para la Atención y Reparación de las Víctimas. Disponible en línea http://escuela.unidadvictimas.gov.co/cartillas/Conpes_ESCUELA.pdf [consultado el 16 de agosto de 2017]. 
establecen acciones específicas para alcanzar los objetivos propuestos, más allá de las acciones misionales [...]. Los documentos CONPES carecen de efecto vinculante dado que el CONPES es un organismo colegiado, de carácter supraministerial, y sin personería jurídica, por lo que sus actuaciones no tienen capacidad jurídica para crear o para ser sujeto de obligaciones ${ }^{23-24}$.

Por consiguiente, los documentos CONPES si bien constituyen un instrumento blando de organización de la función administrativa ya que no involucran una decisión administrativa particular o general con efectos inmediatos (porque así lo determina su marco jurídico y la jurisprudencia), están dispuestos para resguardar la unidad de acción de todas las entidades del Estado colombiano y materializar propósitos específicos que para cada materia de interés general ha delineado el ente máximo de planeación nacional, como organismo asesor y consultivo. Son la hoja ruta o guía de las entidades estatales para el logro de objetivos que superan lo misional, ya que intentan engranar y sincronizar todo el andamiaje estatal con las políticas públicas del más alto nivel, fundamentalmente, económicas y de desarrollo social, por ello, sus niveles de cumplimiento son seguidos con rigor por el DNP en los entes responsables, al punto de determinar o no la inyección de presupuesto.

Estas breves referencias de dicha herramienta comprueban su importancia en la conducción del Estado colombiano, dado que sirven de base para la formulación de políticas públicas y la atención de necesidades de orden social, económico y ambiental. Establecen objetivos específicos de acción estatal y de responsabilidades concretas. Además, determinarán decisiones administrativas y hasta la expedición de leyes o decretos. Por lo tanto, su falta de vinculatoriedad, ausencia de una relación de jerarquía vertical y naturaleza coordinadora y orientadora revelan sus matices jurídicos en lo que conocemos como herramientas de soft law administrativo o derecho blando.

\subsection{LAS CiRCULARES DE SERVICIO COMO INSTRUMENTO}

BLANDO DE ORIENTACIÓN ESTATAL

Es claro que para conducir un organismo del Estado es ineludible que los cargos directivos o las dependencias delegadas unifiquen y orienten sus actividades por medio de instrucciones que consoliden criterios de aplicación e

23 Según lo afirmó el Consejo de Estado, en sentencia del 16 de mayo de 2017. Además en la radicación de la OAJ, GCAL 20133200227051 del 19 de marzo de 2013, se menciona que los documentos CONPES de política no se pueden clasificar como actos administrativos porque no modifican el ordenamiento jurídico, ni producen efecto jurídico alguno.

24 Guía metodológica para la elaboración y seguimiento de documentos CONPES, versión 6. Disponible en línea https://www.dnp.gov.co/CONPES/Paginas/conpes.aspx [consultado el 16 de agosto de 2017]. 
interpretación normativa para asuntos de interés de la entidad, los cuales no siempre están decantados por la jurisprudencia. Para el efecto, las entidades estatales recurren frecuentemente al uso de las circulares de servicio que van dirigidas hasta el último empleado de la entidad y/o al público en general. La mayoría de ocasiones tienen el propósito de dar a conocer cómo deberá abordarse una eventual situación o asunto de relevancia o competencia de la entidad, estas son las circulares interpretativas. Se procura resguardar la unidad de acción estatal, pues sería antitécnico, verbi gratia, que una seccional con determinada competencia territorial de una unidad administrativa especial del orden nacional tuviera criterios distintos a las demás seccionales. En consecuencia, estamos ante una facultad implícita de toda autoridad estatal colombiana dispuesta al logro eficiente y oportuno de los cometidos constitucionales y legales de cada entidad, ya que si bien es dable inferirla del artículo 41 de la Ley 489 de 1998, aquella norma no contempla todas las autoridades públicas existentes en el andamiaje administrativo del Estado colombiano (faltarían los organismos autónomos, órganos de control y unidades administrativas especiales). De modo tal que a través de esta herramienta administrativa se otorga vigencia a los principios de seguridad jurídica, transparencia, publicidad, moralidad, eficacia y buena fe (artículos 2, 83 y 209 de la C.P.), que guían la actividad administrativa.

El uso de circulares de servicio es una práctica habitual e inveterada en la actividad administrativa colombiana, puesto que a los cargos del Estado de dirección y manejo, así como los habilitados en los manuales de funciones, teniendo en cuenta las características propias de cada entidad estatal, se les reconoce constitucional y legalmente (artículos 189,8 y 208 de la C.P.) el ejercicio de funciones de dirección, control, planificación, administración de personal, orientación, coordinación, evaluación y promoción. Esto impone la necesidad de proferir pronunciamientos para la ordenación interna de los servicios y dependencias, parámetros comunes de toma de decisiones, precisión de aspectos procedimentales y la manera de entender normas que en un momento dado requieran ser aplicadas.

Lo llamativo de estos actos de sutil dirección es que no tienen un procedimiento reglado de elaboración y publicidad, por cuanto no encajan en la definición tradicional de acto administrativo ${ }^{25}$. Por consiguiente, es usual que

25 La doctrina francesa, al respecto, señala: "Las circulares aún no hace parte de la 'doctrina administrativa', pero en la práctica tiene efectos directos (en materia fiscal) o indirectos, lo cual plantea la cuestión de su publicidad. [...] El fallo CE, 23 février 2011, 'Ass. Cimade' declaró obligatoria la publicación en ese sitio de las antiguas circulares, las cuales, en su defecto, serán consideradas como derogadas. La revolución Internet hace salir las circulares de la 'clandestinidad'": JACQUELINE MORAND-DevILLER, Derecho administrativo. Temas de reflexión, comentarios y análisis de fallos, 14. ${ }^{a}$ edición, Bogotá: Universidad Externado de Colombia, 2017, pp. 350-353. 
el superior o la dependencia habilitada acuda a un simple acto de comunicación para darlas a conocer a los subalternos o destinatarios. Actualmente, las entidades públicas colombianas las publican en sus sitios web oficiales, deber que se desprende del artículo 8 de la Ley 1437 de 2011. En ese orden de ideas, las circulares garantizan orden, dinámica, coherencia y unidad de la actividad administrativa. El poder de instrucción de la Administración es ínsito y necesario en el Estado de derecho para concretar las funciones del Estado. $\mathrm{Al}$ existir el vínculo jerárquico dentro de la estructura estatal será natural y técnico el uso de esta herramienta ${ }_{i}$ la mayoría de ellas no se proponen crear, extinguir o modificar situaciones jurídicas, sino hacer comprender cierta directriz o encauzar el servicio y, de ese modo, garantizar la unidad de acción en la función administrativa. Es de anotar que la mayor parte de la doctrina española ${ }^{26}$ acogida por la jurisprudencia y la doctrina colombiana, como identificaremos, pacíficamente concibió a las circulares o actos de servicios ad intra, es decir, las dictadas al interior de las entidades estatales, como no susceptibles de control judicial. Esta apreciación militó en la escena jurídica en la medida que se entendía que no existía posibilidad de que afectaran derechos de los particulares. Se aseguraba que por su contenido persuasivo al interior de la Administración no resultan oponibles a los particulares ${ }^{27}$.

Es importante resaltar que también existen circulares de servicios con efectos $a d$ extra; esto es emitidas no solo para el interior de la organización administrativa, sino que abarcan a particulares o usuarios del servicio, y algunas pueden permanecer sin crear, modificar o extinguir una situación jurídica. Ello es usual cuando particulares desarrollan actividades sujetas a la inspección y vigilancia del Estado, y la Administración las suele denominar circulares externas. Son de uso creciente ya que la Carta Política de 1991 demanda publicidad en la prestación de los servicios públicos. La jurisprudencia de nuestro Consejo de Estado, en cuanto a las modalidades de circulares de servicio existentes y su posibilidad de impugnación, refleja los estudios trazados por la doctrina española. En ese sentido, ha manifestado que

las Circulares de Servicios y las Instrucciones Administrativas son susceptibles de ser demandadas cuando las mismas contengan una decisión de la autoridad pública, capaz de producir efectos jurídicos y puedan, en consecuencia, tener fuerza

26 La profesora española Moreno Rebato aclara sobre el punto: "No obstante, tanto Rovovillanova como Garrido Falla, González Pérez y Boquera Oliver, en sus trabajos advierten que en muchos casos las circulares e instrucciones pueden encubrir auténticos reglamentos que, en expresión de Garrido, vienen a delimitar derechos y situaciones jurídicas de los particulares". Mar Moreno Rebato, "Circulares, instrucciones y órdenes de servicio: naturaleza y régimen jurídico", Revista de Administración Pública, n. ${ }^{\circ}$ 147, 1998. p. 161. 
vinculante frente al administrado ${ }^{28}$. En caso de no producir efectos jurídicos, es decir si la circular o instrucción se limita a reproducir lo decidido por otras normas, o por otras instancias, con el fin de instruir a los funcionarios encargados de ejercer determinadas competencias, entonces, no serán actos susceptibles de demanda. También ha expresado esta Corporación que "Si la circular no tiene la virtud de producir esos efectos jurídicos externos, bien porque permanezca en el interior de los cuadros de la Administración como una orientación para el desarrollo de la actividad administrativa, o bien porque se limite a reproducir la decisión de una autoridad diferente, no se considerará entonces un acto administrativo susceptible de control jurisdiccional, porque en dicha hipótesis no se presenta la posibilidad de que los derechos de los administrados sean vulnerados ${ }^{29-30}$.

Últimamente, la jurisprudencia nacional, en similar entendimiento al que tiene la doctrina francesa citada, concibe la existencia de circulares reglamento, denominadas de esa manera porque concretan disposiciones contenidas en la Carta Política, la ley o un decreto; es decir, a través de ellas se disponen normas generales de obligatorio cumplimiento y con consecuencias notables para sus destinatarios, sobre aquellas no ha existido duda de la posibilidad de impugnación ${ }^{31}$.

28 Consejo de Estado, Sala de lo Contencioso Administrativo, Sección Primera, 6 de diciembre de 2001, exp. 2000-6063, Actor: Hugo Palacios Mejía.

29 Consejo de Estado, Sala de lo Contencioso Administrativo, Sección Primera, 3 de febrero de 2000, exp. 5236, Actor: Ricardo de Jesús Osorio Sáenz.

30 Consejo de Estado, Sección Primera, sentencia del 18 de mayo de 2011, rad. 11001-0324-000-2004-00253-01.

31 "Por ende, aunque en estricto sentido y desde una perspectiva formal se podría decir que tales instrucciones no constituyen parte de esa normatividad (de acuerdo con el Diccionario de la RAE instruir es ' $[\mathrm{d}] \mathrm{ar}$ a conocer a alguien el estado de algo, informarle de ello, o comunicarle avisos o reglas de conducta'), desde una óptica material es visible que tales orientaciones o preceptos, al precisar detalles sobre la forma como se debe cumplir de manera general la normatividad aplicable y estar revestidos de la coercibilidad que le imprime la amenaza de sanción de su incumplimiento, poseen un claro tinte normativo. Por lo tanto, no hay duda que aunque el enunciado del artículo 130.7 de la Ley 1438 de 2011 separe la normativa del SGSSS de las circulares de instrucción, en un sentido material forman parte de ese bloque normativo, y son expresión del poder normador que la Constitución ha otorgado a la Administración en aras de facilitar y promover el cumplimiento de sus responsabilidades (artículos 122 y 123). En últimas, como ha señalado la jurisprudencia de esta Sala, '[e]l Presidente de la República es, ciertamente, el titular constitucional de la potestad reglamentaria, pero ello no quiere decir que dentro de su ámbito de competencia y nivel de subordinación jerárquica y normativa, las demás autoridades administrativas no pueda adoptar medidas de carácter general a fin cumplir o hacer cumplir las disposiciones superiores relativas a los asuntos a su cargo, de donde, como titulares de autoridad administrativa, están investidas de las facultades o potestades propias de la administración, dentro de las cuales está justamente la reglamentaria. De allí que los actos administrativos generales pueden emanar de cualquier autoridad administrativa, en lo que concierna a los asuntos a su cargo. En consecuencia, la adopción de la medida acusada no implica, por su alcance reglamentario, usurpación de la correspondiente potestad presidencial'. [...] En 
La jurisprudencia ha distinguido otra modalidad de circulares, las denominadas circulares informativas. En cuanto aquellas, el Consejo de Estado ha indicado que se trata de "cada una de las cartas o avisos iguales dirigidos a diversas personas para darles conocimiento de alguna $\operatorname{cosa}^{1132}$; es decir, el funcionario que las suscribe manifiesta sus consideraciones sobre un aspecto en particular, pueden ser informaciones dirigidas a un determinado sector o grupo de personas públicas o privadas interesadas en el asunto o servicio. Esta modalidad por su finalidad, al igual que las circulares interpretativas, evidentemente no encaja en la típica definición de acto administrativo.

\subsection{LA REGLA JURISPRUDENCIAL INVETERADA}

SOBRE LA NO CONTROLABILIDAD DE LAS CIRCULARES DE SERVICIO

Pese a la notable importancia jurídica de este instrumento de conducción estatal, como lo podemos identificar, la jurisprudencia inveterada del Consejo de Estado colombiano consideró reiteradamente a las circulares de servicio, que tienen un propósito meramente persuasivo, orientador y coordinador -que son la mayoría de estas expresiones-, como no susceptibles de control judicial. El fundamento esencial de ese razonamiento descansó en considerarlas desprovistas de la intención de crear, extinguir o modificar relaciones jurídicas; es decir, carentes de fuerza vinculante. Por ende, no son asimilables a un típico acto administrativo. Se les resta sin mayor profundidad su valor jurídico y figuración dentro del engranaje jurídico-administrativo. Se insiste en que no existe en ellas una "decisión" objeto de control. Efectivamente, verbi gratia, en el asunto radicado bajo el n. ${ }^{\circ} 5236$ de 2000 (C.P. Urueta Oyola), la Sección Primera del Consejo de Estado, en sentencia del 3 de febrero 2000, reiteró la anterior postura. Concluyó que la circular de servicio acusada no podía ser controlada judicialmente porque no creaba, extinguía o modificaba una situación jurídica.

En el caso mencionado se demandaba la nulidad de una circular expedida por la jefe de la Oficina Nacional de Normativa y Doctrina de la Unidad Administrativa Especial Dirección General de Impuestos y Aduanas Nacionales, en la cual se precisaban los alcances de la sentencia C-130/98, relacionada con la aplicación del artículo 5 de la Ley 218 de 1995. Aquella norma es conocida como la Ley Páez, mediante la cual se establecieron incentivos tributarios para la transformación del aparato productivo caucano y la atracción de inversión al departamento del Cauca. El actor planteó que la circular demandada interpretó un punto, que ni la Ley o la sentencia de la Corte Constitucional abordaron,

su valor normativo, derivado del carácter general y abstracto de las reglas que impone, radica la principal diferencia entre las circulares instructivas, como la que se analiza, y las denominadas circulares de información". Consejo de Estado, Sección Primera, sentencia del 13 de octubre de 2016, rad. 11001032400020130025700.

32 Consejo de Estado, Sección Primera, sentencia del 7 de septiembre de 2000, exp. 6152. 
esto es, el período en que se debía solicitar el menor valor del impuesto a pagar. En ese orden, la administración tributaria interpretaba que entendía que debía hacerse en el mismo período gravable en que se efectuó la inversión.

En ese escenario, el Consejo de Estado sostuvo en aquella providencia que "Si la circular no tiene la virtud de producir esos efectos jurídicos externos, bien porque permanezca en el interior de los cuadros de la Administración como una orientación para el desarrollo de la actividad administrativa, o bien porque se limite a reproducir la decisión de una autoridad diferente", no se considera un acto administrativo susceptible de control jurisdiccional, en razón a que "no existe posibilidad de vulnerar derechos de los particulares".

De acuerdo con el anterior lineamiento, el Alto Tribunal mencionó llanamente que el acto acusado se limitó a transmitir instrucciones a los funcionarios competentes sobre la forma cómo, a la luz de la jurisprudencia de la Corte Constitucional, debe entenderse el artículo 5 de la Ley 218 de 1995, en materia de deducciones tributarias y de rentas exentas, dentro del marco de la llamada Ley Páez, sin agregar nuevos elementos. Por ende, no se consideraba un acto pasible de control judicial. El caso descrito llama la atención porque de ser verídico el razonamiento propuesto en la demanda, es indudable que estuvo en juego un recaudo tributario menor o mayor para el Estado del impuesto de renta, ya que no es lo mismo aplicar aquella deducción legal en el mismo periodo gravable en que se hizo la inversión, que en los siguientes.

Lo expuesto en este caso y reiterado en varias oportunidades por el Consejo de Estado colombiano denota que así las circulares informativas o interpretativas sean actos de la Administración con carácter persuasivo u orientador para los operadores de la Administración o el público en general, desprovistas de una decisión administrativa obligatoria, directa y vinculante; es decir, derecho blando o soft law administrativo. Es indudable que por el hecho de emanar de un funcionario o dependencia superior con efecto disuasivo, condicionan indefectiblemente la actividad estatal directa o indirectamente. Es más, la experiencia demuestra que sería ilógico e irracional que un servidor público omita este tipo de circulares porque no son "obligatorias o vinculantes", cuando se conoce que provienen de un superior funcional o producto del principio de coordinación entre entidades públicas, con la posibilidad de enfrentarse a responsabilidades disciplinarias por un comportamiento omisivo, que falte a la unidad de acción administrativa, al poder de instrucción o al principio de colaboración armónica.

\subsection{Algunas manifestaciones modernas del soft LaW administrativo Y SU INCORPORACIÓN EN LA ESCENA JURÍDICA COLOMBIANA}

La utilización de estos instrumentos de dirección persuasiva ofrecen grandes ventajas a la Administración ya que reduce los costos administrativos que implica la adopción de medidas coercitivas, incrementa los índices de cumplimiento 
en razón a la concertación y participación de los actores, y ofrece libertad en la adopción de medios tecnológicos ${ }^{33}$. Así las cosas, para efectos de identificar herramientas de derecho blando es menester realizar un barrido casuístico en la escena jurídica que ratifican su utilización en el derecho administrativo colombiano moderno y, posteriormente, profundizaremos sobre la necesidad de su control. En general, ninguno de ellos goza de consagración legal ni tiene régimen definido por el legislador, lo que naturalmente no implica que contravengan la normatividad superior. Sin ánimo de exhaustividad, a continuación pasaremos a detallar algunos de estos instrumentos que desempeñan un papel relevante en nuestro sistema jurídico administrativo actual.

\subsubsection{Las "guías" que profiere la Agencia Nacional de Contratación Pública, Colombia Compra Eficiente}

Según el artículo 2 del Decreto Ley 4170 de 2011, Colombia Compra Eficiente (CCE) es un ente rector que tiene por objeto desarrollar e impulsar políticas públicas y herramientas orientadas a la organización y articulación de los partícipes en los procesos de compras y contratación pública, con el fin de lograr una mayor eficiencia, transparencia y optimización de los recursos del Estado. Es un organismo que coopera contra el fenómeno de la corrupción, situación de las democracias posmodernas que la nueva gobernanza repudia. En tal virtud, según el artículo 3 numeral 10 ibídem, unas de las funciones de este organismo es "Difundir las normas, reglas, procedimientos, medios tecnológicos y mejores prácticas para las compras y la contratación pública, y promover y adelantar con el apoyo y coordinación de otras entidades públicas cuyo objeto se los permita, la capacitación que considere necesaria, a fin de orientar a los partícipes en el proceso contractual". Es decir, es un ente pedagogo sobre mejores prácticas contractuales que los actores de la contratación estatal deben tener en cuenta al momento de desarrollar los procesos contractuales o de participar en los mismos.

Lo anteriormente implica que esta unidad especial de carácter autónomo, adscrita al Departamento Nacional de Planeación, respeta las competencias constitucionales y legales de planeación, instrucción, decisión y ejecución que están asignadas por la Ley 80 de 1993 y normas especiales sobre la contratación

33 Estas características evidentemente generan beneficios correlativos, esto es, económicos para los interesados o particulares por la generación de productos con valor agregado (sellos de calidad, diversidad de productos, uso eficiente de recursos, tolerancia ambiental, etc.) y la modernización de procesos en diversos escenarios (educación, salud, infraestructura, servicios públicos, sectores de la economía, medio ambiente y desarrollo sostenible). Al tiempo, el Estado se ve beneficiado por la consecución eficiente de intereses superiores, la participación cooperativa de particulares en la gestión de intereses públicos y la profundización de la democracia. 
estatal al interior de cada entidad del Estado, así como las propias de los actores particulares. Por este motivo, este ente en estricto sentido no profiere "circulares de servicio" como las que tradicionalmente utilizan las entidades del Estado, así se nutra de aquel nomen iuris para designarlas, ya que esta unidad no es superior jerárquica o funcional de ninguna otra. Tampoco tiene funciones de control o vigilancia sobre la actividad contractual y no posee competencias decisorias respecto a la forma que debe contratar cada entidad del Estado. Por ende, están ausentes elementos indispensables para que se pueda ejercer el poder instructivo en los términos tradicionales. Sus facultades son de otra índole. Se trata de una competencia enteramente sectorial y transversal. Por lo tanto, cuando emplea la aludida función estamos ante verdaderas guías que buscan definir mejores prácticas en la contratación estatal o derecho blando, emitidas por un órgano de apoyo del Estado para el objetivo superior de alcanzar mayor eficiencia y transparencia contractual. Para ilustrar lo anterior, podemos traer a colación la circular externa n. ${ }^{\circ} 13$ emitida por esta unidad especial, dirigida a los "Partícipes del sistema de compras y contratación pública", respecto a la "Subsanabilidad de requisitos y documentos que no otorgan puntaje". A su turno, reseñaremos algunas observaciones que ratifican la necesidad de que sobre esta herramienta de soft law administrativo colombiano exista al menos un control desde su punto de vista procedimental, para efectos de garantizar un producto adecuado.

El instrumento mencionado estipula:

La normativa exige a los oferentes, entre otras cosas, (i) estar inscritos en el Registro Único de Proponentes (RUP) salvo excepciones expresas ${ }^{34}$; y (ii) presentar junto con la oferta una garantía de seriedad del ofrecimiento ${ }^{35}$. El incumplimiento de estas exigencias condiciona la validez de la oferta por lo cual el oferente debe cumplir con ellas antes de la adjudicación para que la Entidad Estatal considere su oferta en el Proceso de Contratación.

Se indica que el momento en que el oferente debe cumplir con aquellas exigencias es hasta antes de la adjudicación del contrato. No obstante, sobre el mismo asunto la jurisprudencia del Consejo de Estado ${ }^{36}$ ha precisado que se deben cumplir al momento de presentar la oferta.

La misma circular señala:

(i) Inscripción en el RUP. En los Procesos de Contratación los oferentes deben acreditar que están inscritos en el RUP, incluso cuando presentan su oferta antes de que la inscripción esté en firme. Sin embargo, mientras la inscripción no esté en firme, la Entidad Estatal no 
puede considerar que el oferente está habilitado y evaluar su oferta (destacado fuera del texto).

Con el aparte destacado se da la posibilidad de que un oferente presente su propuesta cuando su inscripción en el Registro Único de Proponentes aún no esté en firme, situación que podría resultar contraria a disposiciones superiores, toda vez que en el RuP constan las condiciones que habilitan al proponente para participar en un proceso de selección (experiencia, capacidad jurídica, financiera y condiciones de organización) y su certificado de conformidad con el artículo 6 de la Ley 1150 de 2007, es decir, es plena prueba de las circunstancias que en él consten. De acuerdo con lo destacado, teniendo en cuenta que la recomendaciones de CCE son actos persuasivos, que no tienen un procedimiento legalmente establecido de emisión ni de supervisión de garantías para sus destinarios, se corre el riesgo de que las entidades estatales se nutran jurídicamente de ellas y desarrollen actuaciones ambiguas e imprecisas, porque verbi gratia, algunas seguirán los lineamientos jurisprudenciales mencionados y otras las que emitió el ente "orientador".

Es relevante tener en cuenta que este tipo de herramientas, pese a su carácter no vinculante, indudablemente hacen parte del orden jurídico colombiano, porque son un insumo jurídico de conducción de la función administrativa, razón por la cual, en un Estado social de derecho donde uno de sus pilares cardinales es la sujeción de todo acto jurídico al principio de juricidad, no es admisible que una guía o recomendación de la Administración contravenga lineamientos legales o jurisprudenciales vigentes. Ello ni siquiera es admisible de un reglamento ordinario. No olvidemos que la cohesión del derecho como un sistema jurídico es una garantía prevista a favor del ciudadano, contrarresta las arbitrariedades del necesario poder del Estado y se expresa en el respeto a la jerarquía normativa derivada del rango superior que se reconoce escalonadamente a las normas que integran el ordenamiento jurídico (Constitución, ley y reglamento). En efecto, es claro que esta herramienta del derecho blando administrativo tiene la potencialidad de persuadir a los actores de la contratación estatal, dado que, precisamente, ese fue el propósito legal de creación de la entidad. Los actores de la contratación estatal perciben estos actos como un mecanismo de uniformidad interpretativa y aplicativa de las normas. En consecuencia, es natural el seguimiento a sus lineamientos, de modo que sus efectos así sean indirectos, son incontrovertibles; condicionan la actividad estatal y la de sus partícipes.

De acuerdo con el profesor Santaella ${ }^{37}$, si bien los lineamientos o guías que emite la CCE no son vinculantes directamente en el orden jurídico colombiano 
conforme a la sentencia C-004 de 2017, ello no significa que sean irrelevantes en el derecho administrativo, ya que proporcionan a la Administración pública criterios adicionales dentro del ejercicio aplicativo de normas jurídicas, acortan la discrecionalidad administrativa cuando ciertas disposiciones ofrecen margen interpretativo y decisorio, lo cual, desde nuestra óptica, es usual en la contratación estatal ya que varias normas aplicables a la materia (Ley 80 de 1993 y Ley 1150 de 2007, entre otras) fueron redactadas con la estructura de principios, es decir, mandatos abiertos de optimización y no como reglas de subsunción. Los beneficios de estas guías en el Estado social de derecho son incontrovertibles ya que generan seguridad jurídica, confianza e igualdad de trato para los coasociados. Sin embargo, se recalca, debe ponerse atención a su proceso de producción y a que su contenido no contenga ambigüedades o disposiciones contra legem, pues el legislador quiso a través de este organismo dotar de transparencia el proceso decisional contractual. Por lo tanto, si a los actores de la actividad estatal se les garantiza a plenitud el derecho a participar en la producción de esta herramienta de orientación de la actividad contractual estatal, seguramente la pedagogía será más actualizada, uniforme y precisa, lo cual, aportaría mejores resultados a la finalidad que se propone. En síntesis, este instrumento no puede situarse como un derecho subrepticio que solo sale a luz cuando se adopta una decisión en concreto. En consecuencia, desde ya, podemos avizorar la necesidad de que estos actos de derecho blando sean controlados, se garantice la participación de los interesados y se ajusten a los lineamientos legales y jurisprudenciales sobre las materias que aborda.

\subsubsection{Las guías ambientales}

La estrategia mundial de producción más limpia y sus conceptos asociados, como el de ecoeficiencia, se fundamentan en la idea de que la contaminación y la acelerada pérdida de recursos naturales constituyen un indicador de ineficiencias en la producción y el uso de productos y servicios. Por esta razón, los Estados deben promover que aquellas ineficiencias sean evitadas, mitigadas o superadas por medio de instrumentos alternativos o novedosos que las nuevas tecnologías y las ciencias promueven, en razón a que los sectores mejoran su desempeño ambiental y, a su turno, generan beneficios económicos. En ese sentido, las guías ambientales sectoriales en nuestro ordenamiento surgieron de la necesidad del Estado colombiano de materializar el aludido compromiso internacional (en el marco del Proceso de Marrakech, el cual es impulsado por la Organización de Naciones Unidas para dar cumplimiento al capítulo III del Plan de Implementación de la Cumbre Mundial de Johannesburgo, 2002), así 
como las políticas públicas internas del Ministerio de Ambiente, que adhieren al mismo concepto y estrategia.

Según la profesora colombiana Erika Castro, las guías ambientales en el ámbito colombiano se proponen orientar "los estudios de evaluación ambiental, mejorarlos, difundir información en tecnologías limpias y agilizar los procesos de licenciamiento en el Ministerio" ${ }^{\prime \prime 3}$. Añade que las primeras guías fueron el producto de un procedimiento de concertación entre gremios y autoridades ambientales en el que se procuró concertar temas esencialmente técnicos, ventajas de las nuevas tecnologías, resultados, disponibilidad, etc., en los procesos de producción. La Resolución 1023 de 2005 (artículos 1 y 2) emitida por el Ministerio de Ambiente, Vivienda y Desarrollo Territorial concibe a las guías como un: "instrumento de autogestión y autorregulación del sector regulado y de consulta y referencia de carácter conceptual y metodológico tanto para las autoridades ambientales, como para la ejecución y/o el desarrollo de los proyectos, obras o actividades contenidos en las guías que se señalan en el artículo tercero de la presente resolución". Y las define como "documentos técnicos de orientación conceptual, metodológica y procedimental para apoyar la gestión, manejo y desempeño ambiental de los proyectos, obras o actividades contenidos en las guías que se señalan en el artículo siguiente".

La profesora Castro ${ }^{39}$ explica que las guías constituyen documentos "de referencia para las autoridades ambientales", las cuales pueden examinar su implementación y realizar las recomendaciones a que haya lugar. Así mismo, existe la posibilidad de que muten de su carácter persuasivo a obligatorio, siempre que la autoridad ambiental decida en un permiso o licencia ambiental aplicar las directrices de una guía en particular. Los artículos 2 y 3 de la Resolución 18-0861 de 2002, en el ámbito de la elaboración de proyectos mineros, precisan que constituyen herramientas de consulta obligatoria y orientación conceptual, metodológica y son suministradas a los mineros interesados.

Sobre la naturaleza jurídica de las guías ambientales, el profesor Santaella estima que tienen un alcance regulatorio y no eximen a los interesados de cumplir con la normatividad ambiental vigente aplicable al desarrollo de su proyecto, obra o actividad (artículo 6 de la Resolución 1023 de 2005). Sin embargo, la nota distintiva a las tradicionales manifestaciones del derecho administrativo es "su finalidad no es engrosar el bloque de legalidad ambiental coactiva (artículos 4, 5, 6 y 7 de la Resolución 1023 de 2005), sino valerse

Erika J. Castro Buitrago, La actuación informal de concertación de la Administración. Un estudio para la reconstrucción dogmática del concepto de actividad administrativa, tomando al derecho ambiental colombiano como sector de referencia, Tesis Doctoral, Universidad Autónoma de Madrid, 2015, p. 369 . Ibíd., p. 384. 
de las oportunidades envueltas en la concertación con el sector privado para apelar y activar su sentido de responsabilidad social" ${ }^{\prime 40}$.

Así entonces, sin necesidad de recurrir a la habitual coacción de las figuras típicas del derecho administrativo, se obtienen mejores indicadores de protección ambiental, en la medida que los sectores o actores involucrados aceptaron adherir a parámetros por ellos mismos concertados con las autoridades ambientales.

Por último, cabe señalar que de acuerdo con lo normado en las resoluciones 1023 de 28 de 2005 y 18 -0861 de 2002, se verifica que las guías no tienen un procedimiento administrativo determinado para su emisión y actualización, razón por la cual estimamos pertinente que una autoridad imparcial verifique el cumplimiento de las garantías constitucionales vigentes a favor de los coasociados. He aquí, sin duda, un problema notable de esta clase de instrumentos, pues no son pocas los reparos que surgen respecto de quiénes deben concurrir para la definición de sus contenidos para poder calificarlos de legítimos e imparciales.

\subsubsection{Acuerdos informales}

La profesora Castro ${ }^{41}$ señala que se tratan de "acuerdos de voluntades entre entidades públicas y personas privadas para coordinar esfuerzos en la obtención de intereses mutuos relacionados con la protección ambiental, que a su vez redundan en beneficio del interés público". En tal virtud, los acuerdos informales no tienen una consagración legal de base, son eminentemente atípicos y no gozan de fuerza vinculante, y tienden a que los actores interesados en una materia de interés general cumplan ciertos estándares ambientales determinados y consensuados con ellos sin necesidad de que les sean impuestos. Debe resaltarse que no todas las actuaciones administrativas deben estar estrictamente detalladas en la ley, ya que el Estado social de derecho per se admite que la Administración bajo la observancia de las garantías fundamentales de los coasociados, la sujeción a las normas superiores (interdicción de actuaciones contra legem) y por medio de la utilización de herramientas creativas, obtenga los fines que la Carta Política le ha trazado. En efecto, si bien el artículo 121 C.P. prohíbe a las autoridades públicas ejercer "funciones distintas de las que le atribuyen la Constitución y la ley", aquella norma no puede ser interpretada exegéticamente y de forma aislada a las demás disposiciones de la misma Carta Política, que promueven decididamente el protagonismo eficaz y eficiente de

40 Héctor Santaella Quintero, "Algunas reflexiones sobre las nuevas formas de actuación administrativa impuestas por el mercado y la técnica y sus implicaciones para la metodología de la ciencia jurídica-administrativa", Revista digital de Derecho Administrativo, n. ${ }^{\circ} 5$, Universidad Externado de Colombia, 2011, p. 91.

41 ERiKa J. Castro Buitrago, La actuación informal..., op. cit., p. 399 
la Administración en la consecución de los fines del Estado (artículos 2, 13, 90 y 209 C.P.). Por ende, se habilita a las autoridades públicas a recurrir, si es necesario, a actuaciones transparentes, eficientes, económicas y eficaces sin que las mismas indefectiblemente deban estar casuísticamente precisadas en la ley, siempre que con ello no se transgredan disposiciones legales y se logre el cumplimiento efectivo de los fines constitucionales. De lo contrario, tendríamos una administración anquilosada y torpe ante las realidades inestables y particulares de la posmodernidad, en abierta contravía de lo estatuido y exigido a ella por los preceptos constitucionales. Sobre el alcance de estos actos, el profesor Santaella ha destacado lo siguiente:

Esta clase de pactos constituyen una expresión de la llamada acción informal de la Administración, esto es, aquella actividad que no se encuentra jurídicamente regulada, pero que no por ello resulta antijurídica ${ }^{42}$. [...] De ahí que puedan celebrarse al margen de las formas comunes prefijadas para la actividad convencional de la Administración por la Ley 80 de 1993. Más que generar obligaciones y derechos jurídicamente exigibles, su contenido se plasma en la definición de reglas de

42 Reconocer la legitimidad de esta modalidad de actuación de la Administración pública supone reformular buena parte del principio de vinculación administrativa a la legalidad y escalar su fundamentación a las normas constitucionales y a la nueva realidad que debe encarar el Estado social de derecho en la actualidad. Esto, por cuanto lo habitual será considerar que "solo donde existe norma hay posibilidades de actuación y decisión administrativa, y que allí donde las autoridades actúen sin estos presupuestos no hay derecho sino arbitrariedad de las autoridades". Cfr. Jaime Orlando Santofimio Gamboa, op. cit., p. 338. En un sentido análogo, A. Montaña Plata, Fundamentos de..., loc. cit., p. 168. Admitir la realidad de las nuevas formas de actuación de la Administración y la posibilidad de obrar sin un fundamento legal explícito, aunque sí con una base normativa clara -en el marco de la Constitución y la ley-y, por tanto, nunca contra legem, supone, pues, una relectura del artículo 121 C.P. y de la tajante prohibición a las autoridades públicas de ejercer "funciones distintas de las que le atribuyen la Constitución y la ley". Resulta imperativo, entonces, apartarse de una interpretación restrictiva de este enunciado y dar cabida a una hermenéutica que amplíe las posibilidades de actuación de la Administración en aras de satisfacer los cometidos que constitucionalmente le han sido encomendados. Como señala Schmidt-Assmann, "el Estado de Derecho no exige la juridificación de toda la actuación administrativa" (Vid. La teoría general del..., loc. cit., p. 66). Lógicamente, esto implica advertir la imposibilidad de restringir indebidamente la libertad de los ciudadanos mediante la utilización de formas de coacción administrativas no habilitadas por el ordenamiento legal. De ahí la importancia del recurso al soft law en esta clase de actuaciones: el ejercicio de autoridad debe contar siempre con una base normativa expresa e inequívoca (Cfr. A. Montaña Plata, Fundamentos de..., op. cit., p. 177). De ahí también la correlativa imposibilidad de encajar las manifestaciones de estas nuevas formas de actuación dentro de las categorías primarias o típicas de las decisiones jurídico-públicas, a saber: resolución, norma o contrato. Vid. sobre esta tipología Alfredo Gallego AnabitarTe, ÁnGel MenéndeZ ReXACH et al., Acto y procedimiento administrativo, Madrid: Marcial Pons, 2001, pp. 27 y ss. 
entendimiento o en la declaración de intenciones que, pese a no resultar coactivas, generan una expectativa de conducta que se espera sea atendida ${ }^{43-44}$.

En ese orden de ideas, es claro que este mecanismo no contiene obligaciones imperativas asumidas por los particulares y la Administración, simplemente, con los acuerdos informales, se busca obtener mayor colaboración de los sectores productivos en la gestión pública ambiental y manejo de recursos, con la finalidad de lograr objetivos de interés general. En este instrumento se puede consignar "la implementación de alternativas de $\mathrm{PML}$, mecanismos de autogestión con el establecimiento de indicadores y metas, consolidación de espacios de concertación entre la Administración y las empresas"45. Por lo tanto, los acuerdos informales por su elaboración o producción altamente participativa alcanzan un grado de aceptación. Constituyen una herramienta de soft law administrativo que busca inducir a determinados sectores al cumplimiento de estándares de calidad que el Estado espera sean aplicados en razón de lineamientos internacionales o políticas públicas, sin la necesidad de que los impongan de forma coercitiva. Por consiguiente, su ejecución condiciona la actividad del Estado e interesados. En ese orden, puede enunciarse como ejemplos las guías ambientales expedidas por el Ministerio de Ambiente, Vivienda y Desarrollo Territorial con asocio de los agentes económicos y productivos que se relacionan con los sectores de los plásticos, textiles, frutas y verduras.

\subsubsection{La remisión del derecho a la técnica}

Pese a su contenido regulatorio, las normas técnicas no son normas jurídicas. En efecto, según la Organización Internacional para la Normalización (ISO), las normas técnicas son:

Especificación técnica u otro documento, accesible al público, establecido con la cooperación y el consenso o la aprobación general de todas las partes interesadas, basado en los resultados conjuntos de la ciencia, la tecnología y la experiencia, que tiene por objetivo el beneficio óptimo de la comunidad y que ha sido aprobada por un organismo cualificado a nivel nacional, regional o internacional ${ }^{46-47}$.

43 Es precisamente en virtud de esta expectativa, que equipara este tipo de acuerdos a los conocidos gentlemen agreements del derecho internacional público, que acaban convertidos en una expresión más del llamado soft law. 
Estos instrumentos, generalmente, son proferidos por organismos de normalización. En Colombia, de acuerdo con el Decreto 2269 de 1993, encontramos al Instituto Colombiano de Normas Técnicas (Icontec) como un ente reconocido por el gobierno, cuya función principal es la elaboración, adopción y publicación de las normas técnicas nacionales y la adopción como tales de las normas elaboradas por otros entes, con una persona jurídica de carácter privado sin ánimo de lucro ${ }^{48}$. En tal sentido, debido a que en el Estado social de derecho el monopolio de conformación del orden jurídico está radicado en los órganos del poder público, prima facie no es factible reconocer a estas entidades la potestad de proferir derecho público coercible. Es más, la naturaleza propia de estas normas demuestra que la adherencia a ellas de parte de los sujetos interesados en las materias que regula es predominantemente voluntaria.

Las normas técnicas se sustentan en el consenso científico y tecnológico, corroborado por la experiencia y resultados satisfactorios en las áreas a las cuales se dirige (economía, medio ambiente, tecnologías, etc.), es decir, su legitimidad descansa en la ausencia de imposición, lo cual implica que la comunidad científica o técnica haya generado algún grado de aceptación relevante a sus directrices. Por ende, la fuerza de atracción de estas normas dependerá en gran parte del reconocimiento de este atributo ${ }^{49}$. En ese orden de ideas, es notable que en la actividad administrativa moderna, las autoridades públicas remitan en normas de hard law (leyes, decretos, resoluciones, actos administrativos) a normas técnicas, es decir, a reglas y principios no obligatorios establecidas por entes de carácter privado, los cuales están legitimados únicamente por el conocimiento de una determinada técnica.

Un ejemplo oportuno para efectos de ilustrar la temática es la Resolución 1555 de 2005 del Ministerio de Ambiente, Vivienda y Desarrollo Territorial, mediante la cual se reglamenta el uso de la etiqueta o sello ambiental. Con este sello de calidad se pretende identificar productos y servicios que incorporen costos ambientales y que contribuyan a la solución de problemas ambientales. Por medio de estos se determinan criterios que garantizan un mejor desempeño ambiental del producto respecto de aquellos sustitutos. El Estado, por medio del ecoetiquetado, busca como meta principal "Sensibilizar a los consumidores y productores colombianos sobre estos nuevos mercados y sus ventajas". Así mismo, "orientar las preferencias de compra de los consumidores nacionales hacia productos con potencial de reducir los efectos e impactos ambientales nocivos a lo largo de su ciclo de vida y con esto incentivar el crecimiento de 
un mercado nacional de productos amigables con el ambiente, que contribuyan con los propósitos del desarrollo sostenible" ${ }^{\prime \prime 50}$.

El mecanismo remite expresamente en su artículo primero a una norma técnica cuyo cumplimiento debe ser certificado para ser acreedor del distintivo. Y refiere que se trata de un documento

voluntario elaborado por categoría o subcategoría de producto de acuerdo a las disposiciones vigentes en materia de normalización y expedido por el Organismo Nacional de Normalización, o la Unidad Sectorial de Normalización respectiva en caso de que exista, que establece los criterios ambientales que los productos deben cumplir para que se les otorgue el derecho de uso del Sello Ambiental Colombiano (Resolución 1555 de 2005) $)^{51}$.

Por consiguiente, si bien la referida resolución en todo su articulado reglamenta detalladamente el procedimiento de adopción por parte del interesado en la ecoetiqueta, en cuanto al contenido y alcances del "documento técnico voluntario" -el sello ambiental colombiano se elaborará y expedirá a través de la norma técnica colombiana o norma técnica sectorial (artículo 12)-y demás normas técnicas a las que remite la resolución (NTC-ISO 14020 y NTC-ISO 14024 , relativas a "Sellos y declaraciones ambientales" y "Rótulos y declaraciones ambientales, rotulado ambiental tipo I", artículo 5), no se tiene claridad sobre la manera en que se garantizará la participación de los interesados y la sociedad en general en la elaboración de su contenido técnico o sustancial. Tampoco se conoce el tipo de supervisión técnica que ejercerá el propio Estado sobre el contenido de las normas a las que reenvía. Por consiguiente, queda en vilo varias garantías constitucionales y principios de la nueva gobernanza en esta herramienta del derecho administrativo blando.

Este punto es de cardinal importancia para los propósitos de este trabajo, porque al no existir reglas procedimentales detalladas en una norma de bard law para la producción de estas herramientas, que sirva de garantía imparcial para la vigencia de los derechos fundamentales y los fines del Estado como lo destaca el profesor Santaella a lo largo de su investigación ${ }^{52}$, es imperativo desde nuestro criterio la preexistencia de controles internos y externos de la Administración que aseguren la legitimidad de las decisiones, su racionalidad, objetividad y coherencia con el orden jurídico, $y$, a su turno, prevengan

50 Apartes de los considerandos de la Resolución 1555 de 2005, expedida por el Ministerio de Ambiente, Vivienda y Desarrollo Territorial. Disponible en línea http://www.minambiente. gov.co/images/AsuntosambientalesySectorialyUrbana/pdf/Sello_ambiental_colombiano/ Resoluci\%C3\%B3n_1555_de_2005_de_los_Ministerios_de_Ambiente_Vivienda_y_Desarrollo_territorial_y_de_Comercio_Industria_y_Turismo.pdf[consultada el 16 agosto de 2017].

51 Ibíd.

52 Héctor Santaella Quintero, Normas técnicas y derecho..., op. cit., p. 190 
daños a los intereses de terceros y el bien común i premisas según SchmidtAssmann ${ }^{53}$ indispensables para confiar en un orden jurídico y otorgar vigencia a las libertades esenciales.

\subsubsection{Códigos de buenas prácticas}

También en la escena administrativa moderna es común encontrar los denominados códigos de buenas prácticas, los cuales constituyen lineamientos (jurídicos o técnicos) que el Estado se propone unificar para que sean adoptados de manera voluntaria por determinados sectores de la economía o de servicios y la propia administración, con la finalidad de que determinados sectores se amolden a estándares unificados de eficiencia, transparencia y garantía de derechos de usuarios y comunidad en general. A título de ejemplo, podemos mencionar la circular externa 028 de 2007 expedida por la Superintendencia Financiera, por medio de la cual el Estado, preocupado por los gobiernos corporativos, adoptó el siguiente documento que denominó "Código de mejores prácticas corporativas" ${ }^{\prime \prime 4}$.

53 Eberhard Schmidt-Assmann, "El concepto de la constitucionalización del derecho administrativo", en La constitucionalización del derecho administrativo. XV Jornadas Internacionales de Derecho Administrativo, Bogotá: Universidad Externado de Colombia, 2014, p. 37.

54 En su texto se puede leer: "Las mejores prácticas de gobierno redundan en beneficio de los propios accionistas de diferentes maneras. Por ejemplo, mediante una mayor generación de valor y una mejor gestión de los riesgos, y asimismo mediante la obtención de mejores condiciones de financiación, debido a una menor percepción del riesgo por parte de acreedores e inversionistas. En este sentido, el buen gobierno corporativo no debe entenderse como un fin en sí mismo, sino como un medio para el logro de estos propósitos. La experiencia internacional demuestra que el mejoramiento de las prácticas de buen gobierno requiere de la acción conjunta de las autoridades gubernamentales, las empresas y los inversionis tas, mediante la combinación de normas obligatorias con esquemas de autorregulación y cumplimiento voluntario. Por esta razón, a iniciativa de la Superintendencia Financiera de Colombia, se conformó un Comité integrado por una amplia base de entidades, para la elaboración del presente Código de Mejores Prácticas Corporativas destinado a los emisores de valores colombianos. El Código se ha estructurado de manera que contenga un conjunto de medidas concretas, que se espera sean incorporadas por los emisores de valores en su actividad diaria, sobre los siguientes temas: (i) Asamblea General de Accionistas, (ii) Junta Directiva, (iii) Revelación de Información Financiera y no Financiera, y (iv) Solución de Controversias. Cada grupo de medidas va antecedido de una breve explicación de las mismas. En todo caso, el Código sigue el principio 'cumpla o explique', de allí que las medidas sean de adopción voluntaria por los emisores de valores, quienes deberán remitir diligenciada, por lo menos anualmente a la Superintendencia Financiera de Colombia, la encuesta de Mejores Prácticas Corporativas que tiene por objeto indicar y describir de manera general, información sobre sus prácticas de Gobierno Corporativo y sobre la adopción de las recomendaciones del Código de Mejores Prácticas Corporativas. En todos los casos, el emisor deberá responder si adoptó o no las medidas recomendadas para el período que esté revelando. Cuando su respuesta sea afirmativa, el emisor deberá explicar la forma y mecanismos por los cuales se asegura tal adopción". Información oficial 
Así las cosas, si bien se trata de una herramienta de adopción "voluntaria" de parte de sus destinatarios, sin duda condicionan su actividad dado que no abandonan su matiz jurídico regulador de conductas emanado del Estado en procura de intereses superiores.

En relación con el tema, también podemos rastrear en la escena administrativa moderna el "Código nacional de buenas prácticas para las estadísticas oficiales" ${ }^{\prime \prime 5}$, expedido en el año 2015 por el Departamento Administrativo Nacional de Estadística (DANE), con la finalidad de mejorar la calidad en los procesos y la producción de las estadísticas oficiales generadas por las entidades pertenecientes al Sistema Estadístico Nacional. En efecto, este documento emitido por el DANE, en su condición de ente rector, coordinador y regulador del Sistema Estadístico Nacional de Estadísticas Oficiales (SEN), recopila un conjunto de reglas prácticas que permiten el mejoramiento de la calidad y la credibilidad de las estadísticas requeridas para el diseño, la formulación, el seguimiento y la evaluación de planes, programas y políticas públicas. Estos lineamientos de mejoramiento estadístico fueron dirigidos a los entes que hacen parte del SEN, es decir, a la mayoría de entidades oficiales ${ }^{56}$. En el documento referido aparecen detallados varios principios, estándares y buenas prácticas para la producción y difusión de estadísticas oficiales, como lo son: "i) independencia profesional, ii) mandato estadístico de recogida de datos, iii) recursos adecuados, iv) imparcialidad y normas, v) confidencialidad, vi) transparencia, vii) compromiso con la calidad, viii) selección de las fuentes estadísticas", entre otros.

Aquel instrumento precisa que todas las entidades pertenecientes al SEN deben implementar las directrices establecidas en el referido código, y si bien no previene una consecuencia jurídica concreta por su inobservancia, es claro que el instrumento por su alcance persuasivo, coordinador y orientador, es decir, derecho blando administrativo, condiciona el accionar estatal en razón a que las entidades oficiales del SEN, según el artículo 2.2.3.2.5 del Decreto 1743 de 2016, son evaluadas permanentemente por el DANE para verificar el cumplimiento de estándares de calidad en la recolección estadística.

Igualmente, se tiene el "Código de buenas prácticas para el despliegue de redes de comunicaciones" de la Comisión de Regulación de Comunicaciones

de la Superintendencia Financiera. Disponible en línea https://www.superfinanciera.gov. co/SFCant/Codigopais/textos/codigopias.pdf [consultado el 16 de agosto de 2017].

55 Departamento Administrativo Nacional de Estadística. Disponible en línea https://www. dane.gov.co/files/sen/bp/Codigo_nal_buenas_practicas.pdf [consultado el 16 de agosto de 2017].

56 Entre ellas podemos enunciar al Ministerio de Hacienda y Crédito Público, el Banco de la República, el Departamento Nacional de Planeación, la Registraduría Nacional del Estado Civil, la Federación Nacional de Departamentos, la Asociación Colombiana de Ciudades Capitales, el Observatorio Colombiano de Ciencia y Tecnología, y la Contaduría General de la Nación. 
(CRC)y la Agencia Nacional del Espectro, expedido en el 25 de junio de 2012, en el que se estandariza las condiciones técnicas de la nueva infraestructura de servicios de telecomunicaciones que se instale en el territorio del país; ello, con el objetivo fundamental de evitar riesgos a la población cercana a estos elementos. Se adujo que el documento se emite

con el fin de lograr el despliegue de la infraestructura de TIC para así superar las condiciones de desigualdad, marginalidad y vulnerabilidad de los usuarios, el artículo 55 de la Ley 1450 de 2011 impone a la Comisión de Regulación de Comunicaciones (CRC), establecer los parámetros para que las Entidades anteriormente mencionadas, en el ámbito de sus competencias, promuevan el despliegue de los componentes de infraestructura pasiva y de soporte, de conformidad con los principios de trato no discriminatorio, promoción de la competencia, eficiencia, garantía de los derechos de los usuarios y promoción del acceso de las personas que habitan en zonas donde tales servicios no se están prestando ${ }^{57}$.

Así como dar cumplimiento a la solicitud dada por la Corte Constitucional en la sentencia T-360 de 2010 para que el Gobierno nacional "establezca canales de comunicación e información con la comunidad" acerca de los verdaderos riesgos que tiene la exposición a los campos electromagnéticos.

En ese sentido, el Gobierno nacional, representado en la CRC y la Agencia Nacional del Espectro, concluyó después de varias reuniones con actores del sector de las telecomunicaciones, la necesidad de que en el país se adopte este documento, por medio del cual se establecen los lineamientos más importantes respecto a: la exposición a campos electromagnéticos, promoción del despliegue y uso de infraestructura, documentos requeridos para el trámite de solicitudes de despliegue de infraestructura, plan de despliegue y consideraciones técnicas para el despliegue de infraestructura de telecomunicaciones, entre otros temas.

Estos aspectos, según el citado mecanismo, son ineludibles para garantizar los siguientes intereses superiores del Estado:

i) el de dar cobertura de todos los servicios de telecomunicaciones al 100\% de la población, ii) mejorar la calidad de los servicios de comunicaciones, iii) impulsar el desarrollo económico a nivel regional y nacional, y iv) evitar afectaciones al medio ambiente o la salud de las personas. Los lineamientos según este instrumento deben ser seguidos de manera autorregulatoria tanto por los proveedores de redes y servicios de telecomunicaciones como por las respectivas Entidades Territoriales ${ }^{58}$.

Código de buenas prácticas para el despliegue de redes de comunicaciones de la CRC y la Agencia Nacional del Espectro. Disponible en línea https://www.crcom.gov.co/recursos_user/Documentos_CRC_2012/Codigo_de_Etica/CodigoBuenasPracticas_25_06_12.pdf [consultado el 16 de agosto de 2017]. Ibíd. 
Por tanto, esta herramienta, similar a la anterior, tampoco previó una consecuencia jurídica concreta por el incumplimiento de la norma, en razón a que fue producto de la participación de los actores interesados - públicos y privados-, recoge una solicitud de la Corte Constitucional ${ }_{i}$ y son parámetros técnicos comunes a las tecnologías de las comunicaciones e infraestructura relacionada y a que el Decreto 195 de 2005 faculta al Ministerio de Tecnologías de la información y las Comunicaciones para inspeccionar de oficio o a solicitud de parte, la instalación y niveles de las fuentes de campo electromagnético. Por lo tanto, es evidente que los destinatarios y las entidades estatales involucradas en los mencionados intereses generales aplicarán aquellos estándares.

\section{LA NECESIDAD DEL CONTROL JUDICIAL DEL SOFT LAW ADMINISTRATIVO COLOMBIANO}

\subsection{FUNDAMENTOS TEÓRICOS QUE IMPIDEN LA IMPUNIDAD DE LA ACCIÓN ESTATAL}

Las llamativas características que hemos resaltado relativas a la agilidad, versatilidad y eficacia del derecho blando con el cual actúa hoy la Administración colombiana, no justifican la ausencia de control judicial ni de otra estirpe, máxime, si se tiene en cuenta que no existe reglamentación en sus procedimientos de emisión. En un Estado social y democrático de derecho como el nuestro es ineludible que el juez natural del control de los actos de la Administración resguarde las garantías de los coasociados y las normas superiores que determinan cualquier actividad o manifestación estatal.

Para sostener el anterior aserto, es oportuno empezar por traer a colación la célebre formulación de Montesquieu, razonada desde la observación de la tendencia del ser humano al abuso del poder, citado por el profesor argentino Tomás Hutchinson "Es una experiencia eterna, que todo hombre que tiene poder tiende a (est porté) abusar de él ${ }_{i}$ llega hasta que encuentra los límites", por ello, es conveniente que "por la naturaleza de las cosas, el poder contenga al poder ${ }^{\prime \prime 5}$.

Es preciso recordar que uno de los pilares del derecho administrativo es el principio del control de la actividad o gestión pública, ya que el Estado social y democrático de derecho supone como principio y regla de funcionamiento el sistema de "pesos y contrapesos" para el ejercicio del poder. Efectivamente, la presencia de controles sobre la actividad administrativa protege la estabilidad del Estado, el equilibrio de poderes, la democracia y la vigencia intemporal de

59 Tomás HutCHinSON, "El sistema argentino de control judicial de la Administración", Anales de la Facultad de Ciencias Jurídicas y Sociales, vol. 7, n. ${ }^{\circ} 40$, p. 157. Disponible en línea http:// sedici. unlp.edu.ar/bitstream/handle/10915/19861/Documento_completo.pdf? sequence $=1$ [consultado el 16 de agosto de 2017]. 
los derechos humanos y garantías fundamentales. El profesor Hauriou (1927), desde antaño, resaltó la importancia del control sobre toda la actividad estatal, dado que beneficia la consolidación de las reglas de una sana y "buena administración". En relación con el tópico precisa:

En esencia, la función administrativa es una gestión de negocios (gestion d'affaires), con todo lo que implica una gestión de negocios [...]. En la institución administrativa, el poder está subordinado a la función administrativa y es regida por principios de derecho extraídos tanto del medio jurídico externo como de la idea directriz de la empresa que esa organización procura realizar. De ahí que esa institución esté sujeta a las reglas de la buena administración pública. Para asegurar que el poder de la institución se ajuste a las reglas de la buena administración se concibe el control jurisdiccional de la administración ${ }^{60}$.

Así entonces, el control judicial sobre la actividad administrativa tiene como finalidad básica proteger y garantizar los derechos constitucionales y fundamentales de los coasociados ante el privilegio del poder radicado en las autoridades públicas. Es de recordar que la lucha contra las arbitrariedades y los excesos de poder de la Administración es una bandera perpetua del derecho administrativo ${ }^{61}$ y constituye un imperativo en el Estado social y democrático de derecho; por ello, el profesor Tomas Ramón Fernández (1991) sostenía que "juzgar a la administración contribuye decisivamente a administrar mejor"62.

El maestro de Toulouse (1927), consciente de la evolución que tendría el derecho administrativo, consideró que el control judicial debía actualizarse coetáneamente a los cambios que se presentan en la gestion administrative: "si la administración acepta cada vez más el debate contencioso, es porque ha incrementado su grado de asociación con el administrado. Y si ella se asocia más íntimamente con el administrado, es porque acepta su colaboración en la gestión administrativa"63.

60 Expuesto por el profesor Augusto Durán MarTíneZ en su ensayo "Reflexiones sobre la definición de derecho administrativo", en Ensayos de derecho público. En memoria de Maurice Hauriou, Bogotá: Universidad Externado de Colombia, Bogotá, 2013, p. 323.

61 El profesor Eduardo García de Enterría (1989), sobre el tema señalaba: "La historia de la reducción de estas inmunidades, de esta constante resistencia que la administración ha opuesto a la exigencia de un control judicial plenario de sus actos mediante la constitución de reductos exentos y no fiscalizables de su propia actuación". Citado por ERNESTO JiNESTA LOBO, "El control jurisdiccional de la Administración pública", Revista Judicial, vol. XX, n. ${ }^{\circ}$ 66, 1997, p. 100. Disponible en línea http://www.ernestojinesta.com/_REVISTAS/ CONTROL\%20JURISDICCIONAL\%20DE\%20LA\%20ADMINISTRACI\%C3\%93N\%20P\%C3\%9ABLICA. PDF [consultado el 16 de agosto de 2017].

62 Ibíd., p. 106.

63 Expuesto por el profesor Luis José BéJAR Rivera en su ensayo "Maurice Hauriou y la gestion administrative. Comentarios sobre sus aportaciones al derecho administrativo", en Ensayos de 
También es oportuno traer a colación las palabras del profesor italiano Ferrajoli, con las cuales recalca la importancia del rol de la jurisdicción en sentido amplio para la consolidación de los Estados sociales y democráticos posmodernos, "que quiere decir sujeción a la ley de los poderes públicos, visibilidad, controlabilidad y responsabilidad en el ejercicio de las funciones públicas, igualdad de todos frente a la ley, ausencia de poderes invisibles, de dobles Estados, de dobles niveles de acción política y administrativa"64.

Este tema tampoco es ajeno a parte de la doctrina del derecho administrativo moderno, el cual describe los cambios que ha trasegado nuestra ciencia, fenómeno que al tiempo reclama un control judicial actualizado a los nuevos paradigmas del quehacer administrativo posmoderno. Y bajo ningún punto de vista tolera la petrificación del control judicial por la novedad de las premisas en que se sustentan los instrumentos de soft law administrativo. En relación con el tema, el profesor Barnés explica:

Ha de reconocerse que si, como aquí se postula, los diques que contenían la disciplina tradicional se abren, su ámbito se expande, con perfiles cualitativos necesariamente distintos. Y en lo que al control judicial de la acción administrativa se refiere, esta habrá de correr en paralelo a la expansión material del derecho administrativo (acción privada ${ }^{65}$, acción exterior ${ }^{66}$, acción "blanda" ${ }^{67}$, acción poderosa ${ }^{68}$ ), de un lado y, de otro, servirse de los adecuados parámetros o cánones ${ }^{69}$ cualquiera que sea la jurisdicción a la que se le atribuya ${ }^{70}$.

En efecto, la Administración de la posmodernidad no responde a una dinámica jerárquica o ministerial, se comporta como una verdadera empresa ya que le corresponde gestionar asuntos de tinte privado, garantizar una adecuada infraestructura y competir en sectores regulados (servicios públicos), entre otras tareas. En consecuencia, no es suficiente el respeto de los derechos de los coasociados y el cumplimiento abstracto del orden jurídico, a la Administración

derecho público. En memoria de Maurice Hauriou, Bogotá: Universidad Externado de Colombia, 2013 , p. 344.

64 Luigi FerRajoli, Democracia y garantismo, Madrid: Editorial Trotta, 2008, p. 212.

65 Administración sujeta al derecho privado; actores privados sujetos al derecho privado, con exigencias y principios del derecho administrativo.

66 Acción exterior de la Administración, sea en foros informales, redes u organizaciones mixtas.

67 Acción que no es ejercicio de autoridad: creación de derecho blando, negociaciones, actuaciones materiales de obtención o gestión de la información.

68 Esto es la acción legislativa-ejecutiva de las súper agencias (bancos centrales, agencias de seguridad alimentaria, del medicamento, etc.).

69 Principios o valores extraídos del derecho público (participación, representatividad, objetividad, imparcialidad, transparencia, motivación, control, etc.).

70 Alberto Montaña Planta, Andrés Ospina Garzón y Javier Barnés Vázquez, op. cit., pp. 48-49. 
de hoy se le exige la consecución eficiente de resultados, mandato prohijado por las normas superiores y compromisos internacionales.

De acuerdo con los matices que caracterizan a la nueva Administración corporativa, es dable señalar que el control judicial debe poner atención a la etapa de producción del soft law administrativo, ya que en su gestación informal podrían generarse espacios propicios para arbitrariedades o inobservancia de las garantías fundamentales de los ciudadanos. En ese sentido, la doctrina destaca:

El derecho administrativo del trabajo en común ya no se ocupa solo de la protección del individuo frente al poder, o de la defensa y procura de los valores colectivos, sino de los mecanismos e instrumentos que hagan posible esa suerte de gobernanza cooperativa: organizaciones y procedimientos administrativos compuestos; colaboración informativa, nuevos repartos de responsabilidades y funciones entre el Estado y la sociedad, con sus consiguientes instrumentos de control y trasvase de principios y criterios de actuación, etc. [...]. Aquí el control judicial habrá de enfrentarse a nuevos problemas, sin perjuicio de los de la defensa de los derechos e intereses individuales que puedan verse afectados. El control lo es antes de la política pública. Y habrá de comenzar por tratar con mayor severidad el procedimiento seguido (en sentido amplio, no necesariamente lineal), por cuanto en estos escenarios no se utilizan procedimientos aplicativos, sino creativos o de innovación. [...] La existencia de zonas inmunes al control judicial ha sido contrarrestada con la proclamación de la universalidad de la jurisdicción, en cuya virtud cualquier controversia que afecte los derechos e intereses de los ciudadanos es susceptible de ser residenciada ante los jueces y tribunales para su defensa y garantía ${ }^{71}$.

La justicia administrativa, como hemos visto, se enfrenta a nuevos problemas no solo del conocido acto unilateral, como lo expone el profesor Barnés, sino que debe ocuparse también del acto consensuado o concertado y del sinnúmero de herramientas a las que la administración creativamente puede recurrir para conseguir los resultados esperados por las normas superiores. La existencia del control judicial constituye un alivio en casos que los demás controles no sean suficientes.

La supervisión de que se han observado las garantías mínimas fundamentales inherentes al Estado social y democrático de derecho en esta clase de manifestaciones, o un control preventivo, correctivo y propositivo, empieza a ser la hoja de ruta de la nueva visión que debe orientar la jurisdicción contenciosa administrativa, sin perjuicio, por supuesto, del control negativo o de anulabilidad que la ha caracterizado tradicionalmente.

El profesor alemán Schmidt Assmann ${ }^{72}$ llama la atención a que las actuaciones informales a las que acude actualmente la Administración se adhieran al 
proceso de constitucionalización del derecho administrativo, lo cual supone, primero, su reconocimiento $\mathrm{y}$, naturalmente, "un mínimo de protección" de los ciudadanos frente a esas actuaciones.

\subsection{Fundamentos CONSTITUCIONALES DEL CONTROL JUDICIAL SOBRE TODA LA ACTIVIDAD ESTATAL}

En el Estado social y democrático de derecho (artículo 1 de la C.P.) se reivindican las garantías del debido proceso porque la norma superior reclama actuaciones estatales fundadas en los principios de igualdad, moralidad, eficacia, economía, celeridad y publicidad (artículo 209 de la C.P.) $;$ de transparencia, responsabilidad, participación, concertación y buena fe (artículo 83 de la C.P.), y de confianza legítima, pro bomine, pro debilis ${ }^{73}$ y pro libertate, entre otros. Todo este marco neoconstitucional supone la garantía fundamental de que las autoridades ante los coasociados no obrarán de forma arbitraria. Estas conquistas constitucionales de nuestro orden jurídico no quedaron al arbitrio de la Administración para ponerlas en vigencia cada vez que recurre al abanico de actuaciones administrativas con las que actualmente cuenta. La autotutela administrativa es relevante pero no suficiente. En efecto, el constituyente de 1991 estimó indispensable el diseño y determinación de órganos autónomos e independientes y, por supuesto, un juez natural de la función administrativa -juez administrativo (artículos 236-238 de la C.P.)-, que garantiza su real acatamiento y observancia. Su vigencia responde al principio constitucional de "colaboración armónica" entre las autoridades públicas (artículo 113 de la C.P. $)^{74}$. En tal sentido, para la actual función administrativa no existen espacios inmunes al escrutinio imparcial y transparente de los demás órganos de poder (rama judicial y órganos de control), dado que estos fueron constituidos constitucionalmente justamente para contrarrestar los posibles excesos de poder (checks and balances) ${ }^{75}$.

Este marco constitucional, como analizamos, contribuye a una actividad estatal más eficiente, creíble, transparente y legitimada. Y, lógicamente, resguarda la racionalidad y proporcionalidad del actuar administrativo. Esta ha sido una nota

73 En la Ley 1437 de 2011, lo podemos ver concretado en los artículos 3.2 y 5.6, entre otros.

74 "[...] a diferencia del modelo absoluto y rígido de separación de poderes, la Constitución de 1991, adopta un sistema flexible de distribución de las distintas funciones del poder público, que se conjuga con un principio de colaboración armónica de los diferentes órganos del Estado y distintos mecanismos de freno y contrapeso entre los poderes". Sentencia C- 574 de 2011.

75 "Esto significa que los derechos de los ciudadanos, se someten a la existencia de diversos controles concurrentes y concomitantes que impiden la superposición de un poder sobre otro, y esto sólo puede llevarse a cabo, cuando el mismo ordenamiento jurídico, otorga los medios suficientes para poner en funcionamiento dichos controles". Corte Constitucional, sentencia T-983A/04. 
distintiva de la jurisdicción contenciosa administrativa colombiana a lo largo de su evolución. En el diseño constitucional colombiano, el juez administrativo fue investido para asumir esta delicada y trascendental misión ${ }^{76}$. Además, la Corte Constitucional estimula que ese ejercicio de control del poder sea decididamente activo y pleno en la defensa de las garantías del Estado social y democrático de derecho ${ }^{77}$. No existe pronunciamiento de la Corte Constitucional bajo el cual se hubiese prohijado una interpretación que restrinja el alcance que debe tener el control judicial sobre actuaciones estatales que impacten de alguna manera la escena jurídica. El enfoque constitucional colombiano es que el control judicial de la actividad estatal sea pleno, integral ${ }^{78}$ y garantista.

\subsection{IMPLICACIONES DE LA LEY 1437 DE 2011}

SOBRE LA IMPUGNABILIDAD DEL SOFT LAW ADMINISTRATIVO

Dentro del proceso de constitucionalización que atraviesa el derecho colombiano, el actual Código de Procedimiento Administrativo y de lo Contencioso Administrativo (CPACA), o Ley 1437 de 2011, pretendió materializar varios mandatos sustantivos que trae consigo la Carta Política de 1991, y que el Decreto 01 de 1984 estaba en mora de actualizar, precisar y profundizar en la regulación de las relaciones de particulares con el Estado. El legislador, conforme a la exposición de motivos del CPACA, se trazó como meta adecuar la legislación administrativa a las condiciones jurídico-constitucionales, sociales, políticas y tecnológicas de la actualidad (exposición de motivos del proyecto de Ley 198 de 2009 al Senado). Al respecto, concordamos con las reflexiones del profesor Santaella ${ }^{79}$, quien expone que el CPACA constituye un

76 "Nótese que, de acuerdo con la fórmula adoptada en el artículo 83 del C.C.A., en el que se define el ámbito de competencia funcional de la jurisdicción de lo contencioso administrativo, en nuestro régimen jurídico todos los actos de la Administración Pública están sometidos al control de legalidad de esta jurisdicción, superándose definitivamente cualquier inmunidad que hubiera podido tener el poder público en el ejercicio de las competencias del Estado". Corte Constitucional, sentencia C-426/02.

77 "Mandato que cobra especial sentido en el contexto colombiano, en el cual, dadas las particularidades de su andamiaje institucional, todos los jueces son constitucionales, y en atención a las condiciones históricas de violencia y exclusión hace que recaiga sobre la justicia una pesada tarea al tiempo que herramientas ingeniosas de acción. [...] En el marco del Estado social y democrático de derecho constituido para la realización de un orden justo, se reclama un mayor dinamismo del juez y una especial sensibilidad con la realidad viviente que le rodea". Corte Constitucional, sentencia SU-768/14.

78 Corte Constitucional, sentencias C-095 de 1998 (M.P. Hernando Herrera Vergara), C-1189 de 2005 (M.P. Humberto Antonio Sierra Porto) o T-060 de 2009 (M.P. Mauricio González Cuervo).

79 Héctor Santaella Quintero, "La Constitucionalización del Derecho Administrativo en Colombia. Análisis de incidencia de la obra del legislador en este proceso", Revista de Derecho, n. ${ }^{\circ} 16,2016$, pp. 354-376. 
"vehículo" de constitucionalización del derecho administrativo, pues si bien gran parte de la jurisprudencia por varios años propició cambios significativos en instituciones del derecho administrativo, era indispensable que el legislador adoptara ciertas determinaciones que están vedadas al rol del juez; decisiones y visiones que generen coherencia con el sistema normativo, la realidad de la administración pública colombiana y las políticas de Estado. La Ley 1437 de 2011 pretende solucionar integralmente problemáticas actuales por las cuales atraviesa la Administración pública. La labor constitucionalizadora del legislador supuso, entre otras cosas, la actualización de institutos procesales y reglas preexistentes.

Por tanto, en palabras de Schmidt Assmann ${ }^{80}$, podemos afirmar que con la vigencia de la Ley 1437 de 2011 tenemos un verdadero "derecho constitucional concretizado", al que la doctrina y jurisprudencia tradicional debe amoldarse. Esta evolución fue producto de la preocupación del propio -juez administrativo-, ya que la iniciativa legislativa la tuvo el Consejo de Estado, al cual le correspondió en no pocas ocasiones solventar tensiones entre normas, instituciones y vacíos del Decreto 01 de 1984 con las normas constitucionales de 1991.

El contexto de actualización del derecho administrativo, como anunciamos, comporta la revisión de varias posturas interpretativas adoptadas bajo la anterior normativa (Decreto 01 de 1984) y la renovación de varias instituciones procesales. Ineludiblemente, en el derecho administrativo colombiano sobrevino un cambio de paradigma avalado después de 28 años por el legislador colombiano.

En ese orden de ideas, para el tema específico de la controlabilidad de manifestaciones de derecho blando utilizadas novedosamente por la Administración, la Ley 1437 de 2011 no dejó espacio de duda para concluir que aquellas expresiones en el ejercicio de la función pública deben ser supervisadas por su juez natural. Para el efecto, podemos remitirnos al artículo 104 ídem que alude a las controversias que conocerá la jurisdicción contenciosa administrativa. La norma dispone:

La Jurisdicción de lo Contencioso Administrativo está instituida para conocer, además de lo dispuesto en la Constitución Política y en leyes especiales, de las controversias y litigios originados en actos, contratos, hechos, omisiones y operaciones, sujetos al derecho administrativo, en los que estén involucradas las entidades públicas, o los particulares cuando ejerzan función administrativa.

Así mismo, el artículo 103 del CPACA advierte:

Los procesos que se adelanten ante la jurisdicción de lo Contencioso Administrativo tienen por objeto la efectividad de los derechos reconocidos en la 
Constitución Política y la ley y la preservación del orden jurídico. En la aplicación e interpretación de las normas de este Código deberán observarse los principios constitucionales y los del derecho procesal.

Es más, el artículo 137 del CPACA contempla la siguiente posibilidad: "También puede pedirse que se declare la nulidad de las circulares de servicio y de los actos de certificación y registro".

El antiguo artículo 82 del CCA alusivo al "objeto de la jurisdicción" se dedicaba a enunciar una serie de asuntos que son de conocimiento de la jurisdicción, con el artículo 103 del CPACA se incorporaron todos los principios constitucionales con notables implicaciones en la interpretación y aplicación de los institutos jurídico procesales del derecho contencioso administrativo. Bajo una lectura sistemática exclusiva del CPACA es factible concluir que todo acto de la Administración con importancia sobre la efectividad de los derechos de los coasociados debe ser controlado por la jurisdicción.

De hecho, todo acto que integre el orden jurídico y tenga la potencialidad de vulnerar el sistema normativo debe ser controlado desde una sus variantes subjetiva (tutela de derechos y garantías) y objetiva (ordenamiento jurídico). El legislador no hizo salvedad alguna. Tampoco condicionó el control judicial a que deba ser únicamente sobre lo que tradicionalmente la doctrina concibe como "acto administrativo". De las circulares de servicio, como expresiones de derecho blando como analizamos, el legislador puntualizó su posibilidad de anulación, lo cual ratifica la ausencia de límites al control de expresiones administrativas de derecho blando. Por lo tanto, al intérprete de la norma por principio de hermenéutica no le es dable formular interpretaciones restrictivas sobre el tema, mucho menos en el escenario constitucional narrado. Es claro que debe otorgársele un efecto útil a la nueva normativa.

La interpretación restrictiva del objeto de la jurisdicción y sustento de la tesis de la no controlabilidad de las circulares de servicio y, en general, de las herramientas de soft law administrativo, descansó en una comprensión literal del texto original del Decreto 01 de 1984. El artículo 82 de aquella norma señalaba precisamente que

La jurisdicción en lo contencioso administrativo está instituida para juzgar las controversias originadas en actos y hechos administrativos de las entidades públicas, y de las privadas cuando cumplan funciones públicas. Se ejercerá por el Consejo de Estado y los Tribunales Administrativos de conformidad con la Constitución Política y la ley.

Es decir, algunos sostenían que la jurisdicción solo podía conocer de controversias derivadas "actos administrativos" y no otro tipo de expresiones de la Administración. Se razonó que el legislador no habilitó al juez administrativo para la supervisión de manifestaciones distintas a ese concepto de la doctrina. 
La jurisprudencia concibió que las demás manifestaciones de la Administración no podían "afectar derechos de los ciudadanos". Se les restó relevancia jurídica.

El legislador colombiano, en el año 2011, fue consciente de que la Administración en la posmodernidad ya no se comporta como hace veinte años. Revisadas las memorias de la Comisión Redactora del $\mathrm{CPACA}^{81}$, observamos que este tema fue un punto de discusión con el propósito de renovar los alcances que tendría el control judicial sobre la actividad administrativa. Al respecto, sus integrantes se cuestionaron: "¿Es conveniente definir las diferentes instituciones del Código, tales como acto administrativo, hecho, reglamento, etc.? ¿En caso afirmativo, qué instituciones se deben definir? ¿Con qué contenido?". A lo que respondieron:

No parece conveniente incorporar definiciones de conceptos o instituciones jurídicas en el Código, por cuanto encasillan al juez en una escuela de pensamiento jurídico determinada, creándole así una camisa de fuerza que se contrapone a su autonomía para decidir. Adicionalmente, las definiciones sobre tales conceptos se enfrentan al cambio constante y acelerado de la realidad y de las relaciones jurídicas, y a la inexactitud o insuficiencia para comprender todas las posibilidades de dichos conceptos en esa realidad. Al respecto se ha recordado la fallida experiencia de incluir definiciones sobre los referidos conceptos en el Decreto 01 de 1984, las cuales fueron derogadas por el Decreto 2304 de 1989, dada su inoperancia e inconveniencia.

Por ende, no cabe duda sobre el ensanchamiento del objeto de la jurisdicción desde la óptica del legislativo, tema que la doctrina y jurisprudencia deben ahondar y que este documento llama la atención a continuar analizando. De manera que el conocimiento de las nuevas herramientas administrativas por parte del renovado juez administrativo, es un reto que debe ser acompañado de la actualización de la teoría de las actuaciones administrativas. Su tarea no puede relegarse de los pormenores de la realidad administrativa, ya que el ciudadano reclama un juez moderno, eficiente y garante de sus derechos. Sin embargo, la jurisprudencia nacional, por varios años (desde 1999 a 2014), pacíficamente determinó que si un acto de la Administración no creaba, extinguía o modificaba una situación jurídica, no era factible ejercer control judicial sobre aquel, ya que no tiene la aptitud jurídica de "afectar" derechos de los coasociados o, en otras palabras, no impacta la escena jurídica en la cual convive. Aquella tesis concibió que esta categoría de actos de la Administración quedan al interior de la entidad para efectos de mantener su unidad de acción, razón por la cual comporta un espacio que el juez y ninguna autoridad

81 Ministerio de Justicia y del Derecho, Sala de Consulta y Servicio Civil del Consejo de Estado y Consejo Superior de la Judicatura, Memorias de la Ley 1437 de 2011, vol. I, Bogotá: Imprenta Nacional, p. 116. 
imparcial puede inmiscuirse, puesto que el poder implícito de dirección de la Administración de carácter no decisorio, no puede ser siquiera verificado por otro poder o autoridad.

Esta percepción jurisprudencial y doctrinal del asunto, en nuestro criterio, respondió a un sesgo seguramente del derecho administrativo francés antiguo, que daba preponderancia a una fuerte burocracia central de la Administración y al temor a que los jueces se inmiscuyeran en políticas públicas. Este nuevo contexto de la administración pública colombiana fue analizado en recientes pronunciamientos de la Sección Primera del Consejo de Estado, a la luz de la Ley 1437 de 2011, y produjo un nuevo examen de la tesis jurisprudencial mencionada, advirtiendo que aquella postura no se amolda a los lineamientos del Estado social y democrático de derecho colombiano ${ }^{82}$. El problema jurídico que reiteradamente se planteó fue el siguiente: ¿Los actos de soft law administrativo -i. e. actos con efectos orientativos, instructivos o informativos al interior de la Administración (ad intra) o hacia los particulares (ad extra)-, por medio de los cuales la Administración conduce u orienta la función administrativa, son susceptibles de control jurisdiccional? En la siguiente tabla se observa la línea jurisprudencial sobre la temática con la que Consejo de Estado respondió:

\begin{tabular}{|c|c|c|c|}
\hline \begin{tabular}{l}
\multicolumn{1}{c}{ Tesis A } \\
No, en la medida \\
en que no crean, \\
modifican ni \\
extinguen una \\
situación jurídica.
\end{tabular} & $\begin{array}{l}\text { - Exp. 5064, Sec. 1, C.P. } \\
\text { Urueta Ayola, 14.10.99 } \\
\text { - Exp. 5236, Sec. 1, C.P. } \\
\text { Urueta Ayola, 03.02.00 } \\
\text { - Exp. 6375, Sec. 1, C.P. } \\
\text { Navarrete Barrero, 01.02.01 } \\
\text { - Exp. 2005-00285, Sec. 1, } \\
\text { C.P. Ostau de Lafont Pianeta, } \\
\text { 19.03.09 } \\
\text { - Exp. 2556-08, Sala Plena, } \\
\text { Sec. 2, C.P. Alvarado Ardila, } \\
\text { 17.05.12 } \\
\text { - Exp. 1575-12, Sec. 2, C.P. } \\
\text { Arenas Monsalve, 20.03.13 } \\
\text { - Exp. 3496-2013, Sec. 2, C.P. } \\
\text { Vergara Quintero, 31.03.14 }\end{array}$ & $\begin{array}{l}\text { - Ley } 1437 \text { de } 2011 \\
\text { - Sec. 1, Exp. 2012-00533- } 01 \\
\text { 27.11.14, C.P. Vargas Ayala } \\
\text { - Exp. 2011-00271-00, } \\
\text { 18.06.15, C.P. García } \\
\text { González }\end{array}$ & $\begin{array}{l}\quad \text { Tesis B } \\
\text { Sí, sin que sea } \\
\text { dable distinguir } \\
\text { su contenido y/o } \\
\text { determinante la } \\
\text { afectación de una } \\
\text { situación jurídica, } \\
\text { ya que no existen } \\
\text { zonas de función } \\
\text { administrativa } \\
\text { inmunes al } \\
\text { control judicial. }\end{array}$ \\
\hline
\end{tabular}

82 "Así, las eventuales equivocaciones del pasado no tienen por qué ser la justificación de inaceptables equivocaciones en el presente y en el futuro. $\mathrm{O}$, en otros eventos, una doctrina jurídica o una interpretación de ciertas normas puede haber sido útil y adecuada para resolver ciertos conflictos en un determinado momento pero su aplicación puede provocar consecuencias inesperadas e inaceptables en casos similares, pero en otro contexto histórico, por lo cual en tal evento resulta irrazonable adherir a la vieja hermenéutica. Es entonces necesario aceptar que todo sistema jurídico se estructura en torno a una tensión permanente entre la búsqueda de la seguridad jurídica-que implica unos jueces respetuosos de los precedentes-y la realización de la justicia material del caso concreto -que implica que los jueces tengan capacidad de actualizar las normas a las situaciones nuevas-". Corte Constitucional, sentencia SU-047/99. 
En efecto, en el año 2014, la referida Sección del Alto Tribunal de lo Contencioso Administrativo precisó que a la luz del actual CPACA no es concebible que existan actuaciones de la Administración que se mantengan en la impunidad, máxime si son en la actualidad a las que con frecuencia se recurre. La sola lectura de los artículos 103 y 104 ídem permiten llegar a esa conclusión. Por ello, aquellas actuaciones deben ser controladas judicialmente. No obstante, en nuestro criterio, se hace necesario una postura unificada de esa Corporación a fin de que el tema quede dilucidado, dado que no es la única sección que por competencia podría conocer de manifestaciones de derecho blando; debe analizarse el contexto posmoderno en que se desenvuelve la Administración. La postura interpretativa que se expone derivada del neoconstitucionalismo, a nuestro juicio, no implica interrumpir, detener, sustituir y mucho menos afectar el funcionamiento normal y eficiente de la Administración que es una virtud finalística del soft law administrativo; por el contrario, es más plausible que una orientación e interpretación de la Administración expresada en un acto antes que se convierta en una decisión concreta o general, o sirva de insumo jurídico para otras se ajuste al ordenamiento jurídico y no sea el cimiento de concepciones, acciones o decisiones antijurídicas. Tampoco es admisible que por la sola imperiosa necesidad de la Administración de alcanzar resultados que las normas superiores le impone se inobserven garantías mínimas fundamentales. Esos riesgos deben ser conjurados por el juez natural, lógicamente, como expondremos, desde una perspectiva actualizada del control judicial.

\subsection{El JueZ del SOFt LaW administrativo, Un JueZ de Garantías}

Como hemos detectado a lo largo de este trabajo, las herramientas de soft law administrativo las caracteriza notablemente su proceso de producción informal y flexible; en las mismas no encontramos una decisión unilateral de las que típicamente profiere la Administración de manera vertical para solventar problemáticas (sanciones, órdenes o asignación, extinción o modificación de derechos). Por ello, no es indispensable la existencia de un procedimiento administrativo estrictamente reglado que garantice con exactitud los derechos y deberes de los involucrados. Evidentemente, a estos instrumentos los destinatarios o coasociados se adhieren voluntariamente porque antes de publicitarse su contenido debió existir un proceso de concertación o participación en el que con seriedad se tuvo en cuenta sus puntos de vista, inquietudes y sugerencias, una verdadera concertación. También por las siguientes características:

- Es una directriz de un alto funcionario de dirección o dependencia instructora de una entidad estatal.

- El contenido de los mismos hace parte de una técnica o ciencia autorizada con un grado de consenso relevante y una norma de bard law sugiere su adopción. 
- Emana de un organismo estatal con función orientadora autorizado legalmente para precisar las temáticas que trata.

- A través de ellos los interesados en las materias reguladas obtienen beneficios -certificaciones de calidad hasta incentivos económicos ${ }^{83}-$ y previenen riesgos jurídicos, lo cual hace atractivo y necesario adoptarlos en su conducta económica, social o ambiental frente a la sociedad.

- Es ejercicio de función administrativa para el logro de políticas públicas y compromisos internacionales.

- Su adopción por parte de autoridades públicas implica el beneplácito de organismos ejecutivos que velan por el cumplimiento eficiente de políticas públicas prioritarias del Estado colombiano.

Es más, podríamos afirmar que esta clase de actuaciones son seguidas en la escena jurídica con mayor apego que un tradicional acto administrativo, dado que tienen como base la aceptación y hasta el compromiso de adherencia de parte de los interesados, o un sustento legal de legitimidad de sus orientaciones que genera confianza en plasmarlas en decisiones administrativas o acciones. En consecuencia, es clara su trascendencia jurídica en el derecho administrativo moderno.

El derecho administrativo colombiano, como hemos notado, materialmente se expandió, lo que naturalmente reclama que el control judicial no quede rezagado a esa evolución. La Administración de la posmodernidad, avalada por la Carta Política, está enfocada en la realización eficiente de políticas públicas y para ello involucra a los interesados; trabaja corporativamente con los actores de la sociedad. De acuerdo con lo anterior, el control judicial que realiza la jurisdicción contenciosa administrativa colombiana ya no solo se enfrenta al problema de mantener el orden jurídico en abstracto, de analizar los alcances de un contrato, de asignar de derechos o de reparar daños antijurídicos, debe verificar también si en esa alta producción regulatoria creativa, informal y flexible de la Administración se acataron las garantías mínimas del debido proceso.

Efectivamente, si bien no es dable predicar una reglamentación severa del procedimiento administrativo para aquellos mecanismos, pues sería totalmente inconveniente para el logro de los principios de eficiencia, celeridad y económica (artículo 209 de la C.P.) que intenta materializar la Administración por su intermedio y, como precisamos, en últimas, es una actuación de adherencia voluntaria, ello no implica, como toda manifestación estatal, el acatamiento del mínimo de garantías que ineludiblemente impone la Carta Política de 1991.

83 Véase, por ejemplo, el Decreto 870 de 2017, por el cual se establece el pago por servicios ambientales y otros incentivos a la conservación. Mediante esta norma el Estado paga incentivos económicos a personas naturales, jurídicas privadas o públicas que de manera voluntaria se adhieran a compromisos voluntarios para el desarrollo de acciones de preservación, restauración de áreas y ecosistemas estratégicos. 
Por lo tanto, para esta categoría de actuaciones administrativas, la perspectiva del control judicial debe tener un matiz distinto, sin perjuicio del tradicional control negativo o anulatorio que eventualmente puede tener cabida.

Es de recordar que el debido proceso es un conjunto de garantías de orden procesal que son exigibles sin importar la clase de procedimiento que se trate. Tiene su origen en el common law y establecía una serie de garantías contra la arbitrariedad del monarca. Constituye un principio y derecho fundamental en nuestro ordenamiento jurídico (artículo 29 de la C.P.). Según la Corte Constitucional -sentencia C-341 de 2014-, cobija todas las manifestaciones administrativas y hace parte de los criterios a seguir en la función administrativa, dado que está estrechamente relacionado con los artículos 209 y 6 de la C.P. (sentencias T-167/13, T-103/06 y T-909/09). Dentro del derecho administrativo moderno cumple una función protectora de los coasociados. La Ley 1437 de 2011 también quiso reivindicar su observancia en todo el que hacer administrativo (artículos 1, 3 y 7 ).

De acuerdo con las características expuestas del derecho blando administrativo, el control judicial debe resguardar la corrección y afirmación de la pública o mandato superior que la Administración busca alcanzar por medio de la herramienta de derecho blando. Para el efecto, se requiere una justicia oportuna, técnica y pronta que tutele las máximas del debido proceso constitucional. El juez deberá supervisar que en ese procedimiento de producción de soft law administrativo la Administración haya garantizado razonablemente la participación de los actores o interesados, permitido el acceso a la información y documentación sobre la actuación, existido la posibilidad de intervenir y las observaciones fueron objetivamente evaluadas, y habido espacios reales de concertación como los que precisa el concepto de nueva gobernanza, entre otras. Ello garantiza no solo la calidad de la regulación, también legitima la actuación administrativa y el contenido al que se llega y, lógicamente, como todo instrumento jurídico del Estado, se cumpla con el principio de juricidad como parte del sistema normativo. Teniendo en cuenta que existe una amalgama de actuaciones que encajan en el concepto de soft law administrativo, el juez, de manera versátil y creativa, debe velar por la observancia de las garantías fundamentales, las cuales están delineadas jurisprudencialmente por la Corte Constitucional desde tiempo atrás. Se sugiere un juez más cercano al modelo norteamericano porque aquel ha tenido mayor contacto con el movimiento de "deslegalización" del derecho administrativo, es decir, con este tipo de herramientas informales. Ello comporta un cambio de visión al tradicional y esquemático juez administrativo al que hemos estado acostumbrados en Colombia.

En Estados Unidos, el derecho constitucional es el punto de partida del control y toda expresión administrativa no tiene el mismo nivel de intensidad de control judicial, ya que algunas veces será relevante el escrutinio de cuestiones puras de derecho y otras las circunstancias fácticas particulares del asunto. El juez norteamericano suele recurrir creativamente a una solución 
que garantice las mínimas garantías y al tiempo la Administración logre sus cometidos de interés general.

En este punto es oportuno a acudir a lo señalado por el profesor español Javier Barnés Vázquez, que analiza la variedad de controles que puede ejercer el juez administrativo:

El control puede ser ex ante o ex post; preventivo o retrospectivo; de eficacia o de la

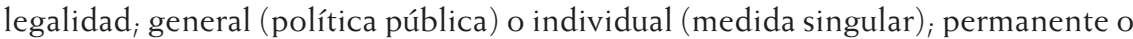
sistemático (evaluaciones periódicas) o puntual y esporádico; afirmativo (evalúa y propone alternativas), o corrector ( si se ajusta o no a lo previsto) [...]. El control judicial, en efecto, es jurídico (el juez lo es de la legalidad, no de la excelencia ni de la eficacia); es un control formalizado; ex pos; iniciado desde afuera de la administración; puntual, eventual o esporádico; y con un enorme potencial sancionador. El control judicial, obvio es decirlo, no convive solitario. La clave del control reside en el arte de la mezcla ${ }^{84}$.

Este cambio de paradigma del derecho administrativo se aleja del conocido proceso de subsunción que le correspondía ejecutar al juez administrativo cuando estaba expuesto a la tradicional controversia anulatoria. El profesor Barnés anuncia también que el examen para estos instrumentos debe trasladarse a su proceso de producción. Las actuaciones administrativas cambiaron en la posmodernidad. Por ende, su control judicial debe acompañarlo con todas las especificidades que conlleva. Sobre el punto, el doctrinante reflexiona:

Si el legislador, por el contrario, apuesta por incentivar la colaboración públicoprivada y los acuerdos medioambientales con las empresas contaminantes, la ley podrá establecer un marco general y flexible (objetivos y plazo mínimos etc.) y renunciar a fijar en detalle el conjunto de prohibiciones y mandatos para cada sustancia contaminante y área, con un plazo determinado, etc. En tal caso, la función del juez consistirá en determinar, entre otras cuestiones (procedimiento, organización o competencia), si el contenido del acuerdo desborda el marco establecido, pero no tendrá por objeto revisar subsunción alguna, puesto que la ley no habría prefigurado materialmente cuál sea el contenido obligatorio del convenio para cada sustancia. [...] cuando el procedimiento se utiliza en el contexto de otros métodos de administración y gobernanza, como los que se caracterizan por dejar abierta en la ley la solución final para diferirla a un complejo procedimiento administrativo (como ocurre, por ejemplo, en el urbanismo, o en el medio ambiente en la Unión Europea, etc.), la atención del juez se centrará precisamente en el procedimiento establecido por la ley, para revisar todos su elementos (participación, colaboración, diálogo y ponderación de todos los intereses, motivación, etc.). El examen de la decisión final, en sí misma considerada, pasa en el control judicial a un segundo p. 66 . 
plano, puesto que la ley no la babría programado o preestablecido [...]. Aquí, la tutela se desplaza hacia el procedimiento y su observancia habría de ser sancionada judicialmente con la mayor severidad ${ }^{85}$.

En síntesis, el juez administrativo colombiano de la posmodernidad debe ser provisionado de herramientas procesales que lo conviertan en verdadero juez de garantías al momento de enfrentarse a una controversia suscitada por estos mecanismos, y, si es del caso, corregir las inobservancias procedimentales mínimas que ampara la Carta Política de 1991 para efectos de que el objetivo político o normador del instrumento administrativo se cumpla. La Ley 1437 de 2011, como advertimos, si bien contempló el conocimiento de estas herramientas, no detalló mecanismos procesales para que el juez administrativo adopte oportunamente correcciones coherentes con las características de estas expresiones. Por lo tanto, proponemos la adopción legislativa de un mecanismo ágil, expedito y oral sobre estas herramientas, bajo el cual el juez administrativo supervise la observancia de las garantías mínimas del debido proceso. Por lo tanto, se propone la existencia de un medio de control específico para el soft law administrativo dentro del CPACA, dado que sus características lo distinguen del tradicional acto administrativo que conoce la doctrina. Es pertinente la presencia de un medio de control coherente con los alcances de estas herramientas, en el que sea factible corregir creativa y dinámicamente las garantías procedimentales de orden constitucional que eventualmente pudo quebrantar la Administración en el proceso de producción y, a su turno, la Administración alcance los propósitos plausibles de las herramientas de soft law administrativo. Se reclama un juez administrativo ante el derecho blando que no sea un convidado piedra. Sin perjuicio, por supuesto, del tradicional control anulatorio que eventualmente pueda tener cabida sobre aquellas herramientas, porque, de todos modos, no dejan de ser instrumento normativo de origen estatal y su contenido de fondo debe estar alineado al sistema normativo.

En el control judicial negativo del soft law administrativo, las causales de anulabilidad que operarían serían las ya conocidas por la doctrina (falta de competencia, falsa motivación ${ }^{86}$, desviación de poder, violación a normas superiores), con excepción de la denominada expedición irregular, ya que estas herramientas no conservan una regulación previamente detallada para su emisión, pero lógicamente, como lo hemos resaltado, deben acatar las garantías mínimas del debido proceso. La causal falta de competencia tendría sus matices, dado que habría que revisar el funcionario que expide la manifestación, pues si bien, por ejemplo, los cargos directivos tienen ese deber de instrucción u orientación claramente radicado y en ocasiones precisado en normas especiales, ello no

86 Por acreditarse esta causal fue anulada una alerta -soft law-del Invima, por parte del Consejo de Estado, Sección Primera, exp. 2011-00271-00, en sentencia del 18 de junio de 2015. 
obsta para que otro tipo de cargos, según los manuales de funciones o bajo la órbita de órdenes superiores, tengan esa función o capacidad de contribuir a la unidad de acción administrativa.

\section{CONCLUSIONES}

La Administración pública colombiana en la actualidad está alineada a los conceptos del "Estado posmoderno" y "gobierno público corporativo". Ello implica para las autoridades públicas asumir con pragmatismo las condiciones altamente cambiantes que sobrelleva la posmodernidad, como son: el cambio climático, las nuevas tecnologías y la ciencia, el neoliberalismo, la globalización y la tendencia desregulatoria, entre otras. Estos escenarios exigen de la Administración actuaciones flexibles, coherentes y rápidamente adaptables a las realidades, enfocadas en la eficacia y la consecución oportuna e integral de resultados que las normas superiores exige y la sociedad reclama. En la actividad administrativa colombiana se constata que proliferan herramientas que encarnan las anteriores premisas, por lo que la Administración recurre al derecho blanco o al soft law administrativo en razón a que no se encasilla en un procedimiento estrictamente reglado que impide muchas veces una solución oportuna, técnica y coherente con la problemática concreta. El derecho blando administrativo encauza de manera más simple, dinámica y democrática las políticas de Estado y de gobierno más apremiantes, y permite además fijar estándares más allá de los que la ley obliga.

El carácter no vinculante de estas herramientas no les resta su vocación normativa dado que intentan incidir en la conducta de los coasociados y, al tiempo, condicionan públicamente el quehacer administrativo. Se razonaba que estos instrumentos no incidían en los derechos y garantías de los coasociados. Aquel argumento lo adoptó la jurisprudencia, al punto de concebir que no era factible controlar judicialmente aquellas expresiones estatales porque no creaban, extinguían o modifican una situación jurídica ${ }_{i}$ es decir, por varias décadas se dejó un espacio de actividad administrativa inmune al control judicial.

Revisada la estructura jurídica de algunas de las herramientas del soft law administrativo colombiano, se advierte como nota común o distintiva la inexistencia de un procedimiento administrativo previo al acto detalladamente reglado que sirva de garantía de los derechos de los destinatarios. Si bien tal aspecto en nuestro criterio no las convierte en actos antijurídicos, pues no dejan de ser actos de adherencia voluntaria y sin la vocación de coaccionar bajo la imposición de un deber, obligación, sanción o modificación de un derecho, al constituir manifestaciones del Estado con un propósito regulador claro y que además cohesionan la unidad de la actividad administrativa, de acuerdo con el actual marco neoconstitucional, debe garantizarse el mínimo de garantías que impone el principio y derecho constitucional al debido proceso. 
El marco constitucional colombiano y su fuerza impregnadora en el derecho administrativo tradicional supuso con la expedición de la Ley 1437 de 2011 la renovación de varios institutos jurídico-procesales y, por supuesto, la inexistencia de espacios de actividad administrativa vedados al escrutinio imparcial del juez administrativo (artículos 103 y 104). Por ello, es dable sostener bajo sus alcances que todo acto que integre el orden jurídico y tenga la potencialidad de vulnerar el sistema normativo debe ser controlado desde sus variantes subjetiva (tutela de derechos y garantías) y objetiva (ordenamiento jurídico). El legislador no hizo salvedad alguna al control judicial de este tipo de herramientas normativas. El CPACA si bien no ofrece dudas para efectos de provocar el control judicial del soft law administrativo, las características propias de estos mecanismos proponen actualizar también el tipo de control que se debe ejercer sobre los mismos, ello, bajo la adopción de un medio de control judicial específico que se incorpore en el CPACA.

\section{BIBLIOGRAFÍA}

\section{DOCTRINA}

Agudo GonZÁLEZ, JorGE. "La concertación con la administración", Opinión Jurídica, vol. 10, n. ${ }^{\circ}$. Disponible en línea http://dialnet.unirioja.es/servlet/revista?codigo $=13860$.

Alli Aranguren, Juan-Cruz. Derecho administrativo y globalización, Madrid: Editorial Aranzandi, 2004.

BéjAR Rivera, Luis José. "Maurice Hauriou y la gestion administrative. Comentarios sobre sus aportaciones al derecho administrativo", en Ensayos de derecho público. En memoria de Maurice Hauriou, Bogotá: Universidad Externado de Colombia, 2013

BenAVIDES, José Luis, y ANDrés Ospina (comp.). Contribuciones para el sistema de precedentes jurisprudencial y administrativo. Bogotá. Universidad Externado de Colombia, 2014.

Bordalí Salamanca, Andrés. "La Administración pública ante los tribunales de justicia chilenos", Revista Chilena de Derecho, vol. 33 n. o 1, 2006, 17-36.

Castro Buitrago, Erika J., "Aproximación al concepto de gobernanza en Colombia y algunos apuntes sobre su importancia en el derecho ambiental", Opinión Jurídica, vol. 10, n. ${ }^{\circ} 20,2011$.

Castro Buitrago, Erika J., La actuación informal de concertación de la Administración. Un estudio para la reconstrucción dogmática del concepto de actividad administrativa, tomando al derecho ambiental colombiano como sector de referencia, Tesis Doctoral, Universidad Autónoma de Madrid, 2015. 
Chevallier, Jacques. El Estado posmoderno, Bogotá: Universidad Externado de Colombia, 2014.

Constitucionalización del derecho administrativo, t. II, El derecho administrativo para la paz, XVII Jornadas Internacionales de Derecho Administrativo, Bogotá: Universidad Externado de Colombia, 2016.

Durán Martínez, Augusto. "Reflexiones sobre la definición de derecho administrativo", en Ensayos de derecho público. En memoria de Maurice Hauriou, Bogotá: Universidad Externado de Colombia, Bogotá, 2013.

Ferrajoli, Luigi. Democracia y garantismo, Madrid: Editorial Trotta, 2008.

Heller, Hermann. Escritos políticos, Madrid: Alianza Editorial, 1985.

Matilla Correa, Andry, Jaime Orlando Santofimio Gamboa y Héctor Santaella Quintero (coords.). Ensayos de derecho público. En memoria de Maurice Hauriou, Bogotá: Universidad Externado de Colombia, 2013.

Ministerio de Justicia y del Derecho, Sala de Consulta y Servicio Civil del Consejo de Estado y Consejo Superior de la Judicatura. Memorias de la Ley 1437 de 2011, 3 vol., Bogotá: Imprenta Nacional.

Misión de Cooperación Técnica en Colombia del Consejo de Estado Francés. Memorias Seminario Franco-Colombiano sobre la Reforma a la Jurisdicción ContenciosoAdministrativa, 7 a 11 de julio de 2008 (CD-ROM).

Montaña Planta, Alberto, Andrés Ospina Garzón y Javier Barnés VázQuez, "Justificación, retos y aporte al derecho administrativo", en 100 años de la jurisdicción de lo contencioso administrativo. XIV Jornadas de Derecho Administrativo, Bogotá: Universidad Externado de Colombia, 2014.

Morand-Deviller, JaCqueline. Derecho administrativo, Temas de reflexión, comentarios y análisis de fallos, 14. ${ }^{a}$ edición, Bogotá: Universidad Externado de Colombia, 2017.

Moreno Rebato, Mar. "Circulares, instrucciones y órdenes de servicio. Naturaleza y régimen jurídico", Revista de Administración Pública, n. ${ }^{\circ}$ 147, septiembre-diciembre de 1998.

SÁnChez Pérez, AleXAnder. Las normas de derecho blando. Un análisis jurídico de los efectos de la reserva de instrucción sobre el derecho territorial. Bogotá: Universidad Externado de Colombia, 2012.

Santaella Quintero, Héctor. "Algunas reflexiones sobre las nuevas formas de actuación administrativa impuestas por el mercado y la técnica y sus implicaciones para la metodología de la ciencia jurídica-administrativa", Revista digital de Derecho Administrativo, n. ${ }^{\circ}$ 5, Universidad Externado de Colombia, 2011. 
Santaella Quintero, Héctor. "El doble nivel, vinculante y no vinculante, de la contratación pública en Colombia", en Contratos públicos. Problemas, perspectivas y prospectivas, Jornadas Internacionales de Derecho Administrativo XVIII, Bogotá: Universidad Externado de Colombia, 2017.

Santaella Quintero, Héctor. "La constitucionalización del derecho administrativo en Colombia. Análisis de incidencia de la obra del legislador en este proceso", Revista de Derecho, n. ${ }^{\circ}$ 16, 2016.

Santaella, Héctor. "La sujeción de la Administración a los precedentes judiciales", Contribuciones para el sistema de precedentes jurisprudencial y administrativo, Bogotá: Universidad Externado de Colombia, 2014.

Santaella Quintero, Héctor. Normas técnicas y derecho en Colombia. Desafíos e implicaciones para el derecho en un entorno de riesgo, Bogotá: Universidad Externado de Colombia, 2008.

Santofimio Gamboa, Jaime Orlando. Tratado de derecho administrativo. Introducción a los conceptos de la administración pública y el derecho administrativo, 3. a edición, Bogotá: Universidad Externado de Colombia, 2003.

Sarmiento, Daniel. El soft law administrativo. Un estudio de los efectos jurídicos de las normas no vinculantes de la Administración, Madrid: Editorial Aranzandi, 2008.

Sartori, Giovanni. Elementos de teoría política, Madrid: Alianza Editorial, 1992.

SCHmidt-Assmann, Eberhard. "El concepto de la constitucionalización del derecho administrativo", en La constitucionalización del derecho administrativo. XV Jornadas Internacionales de Derecho Administrativo, Bogotá: Universidad Externado de Colombia

SCHMidT-AsSmann, EBerhaRd. La teoría general del derecho administrativo como sistema. Madrid: Marcial Pons Ediciones, 2003.

Seminario Internacional de presentación del Nuevo Código de Procedimiento Administrativo y de lo Contencioso Administrativo. Ley 1437 de 2011. Consejo de Estado (CD-ROM).

\section{DOCUMENTOS ELECTRÓNICOS}

Aguilar, Luis F. "La gobernanza de los asuntos públicos, Centro de Gobernanza Pública y Corporativa Universidad del Turabo", Cátedra Magistral, Instituto de Investigación en Política Pública y Gobierno, Universidad de Guadalajara, 25 de marzo 2014. Disponible en línea http://ut.suagm.edu/sites/default/files/uploads/ Centro-Gobernanza/CATEDRAL_ANUAL/La-Nueva-Gobernanza-Publica. PR.UT.pdf. [Consultad el 21 de octubre de 2017].

HutCHInSON, TOMÁs. "El sistema argentino de control judicial de la Administración", Anales de la Facultad de Ciencias Jurídicas y Sociales, vol. 7, n. ${ }^{\circ}$ 40. Disponible en línea 
http://sedici. unlp.edu.ar/bitstream/handle/10915/19861/Documento_completo. pdf? sequence $=1$. [Consultado el 16 de agosto de 2017].

Jaramillo C., Marcos y José Luis Lara A. "Acerca del denominado 'soft law administrativo': notas frente a la experiencia japonesa y chilena", Archivo Philippi - n. ${ }^{\circ}$ 292028 v1. Disponible en línea http://www.derecho.uba.ar/institucional/pacem/ el-soft-law-administrativo.pdf.

Jinesta Lobo, ERnesto. "El control jurisdiccional de la Administración pública", Revista Judicial, vol. xx, n. ${ }^{\circ} 66$, septiembre de 1997. Disponible en línea http://www. ernestojinesta.com/_REVISTAS/CONTROL\%20JURISDICCIONAL\%20DE\%20LA\%20 ADMINISTRACI\%C3\%93N\%20P\%C3\%9ABLICA.PDF. [Consultado el 16 de agosto de 2017].

"Los 'Administrative Law Judges' norteamericanos: imparcialidad administrativa y control judicial". Madrid: Centro de Investigación Sobre Justicia Administrativa, Universidad Autónoma de Madrid. Disponible en línea http://cija-uam.org/ losadministrative-law-judges-norteamericanos-imparcialidad-administrativa-ycontrol-judicial/.

Morandé, Pedro. "Perspectivas para el pensamiento social católico", Revista Teología y Vida, vol. 49, n. ${ }^{\circ} 3,2008,457-465$. Disponible en línea http://dx.doi.org/10.4067/ S0049-34492008000200016.

\section{JURISPRUDENCIA}

Corte Constitucional, sentencia C-160 de 2000.

Corte Constitucional, sentencia C-426/02.

Corte Constitucional, sentencia T-983A/04

Corte Constitucional, sentencia T-360 de 2010.

Corte Constitucional, sentencia C- 574 de 2011.

Corte Constitucional, sentencia SU-768/14

Corte Constitucional, sentencia C-004 de 2017.

Consejo de Estado, Sección Primera, sentencia de 10 de febrero de 2000, rad. 5410.

Consejo de Estado, Sección Primera, sentencia de 7 de septiembre de 2000, exp. 6152.

Consejo de Estado, Sección Primera, sentencia del 18 de mayo de 2011, rad. 11001 03-24-000-2004-00253-01.

Consejo de Estado, Sección Tercera, sentencia de 12 de noviembre de 2014, exp. 29.855. 
Consejo de Estado, Sección Primera, 13 de octubre de 2016, rad.110010324000 20130025700.

\section{Sitios Web OFICIALES CONSULTADOS}

Agencia Nacional de Contratación Pública, Colombia Compra Eficiente. Disponible en línea https://www.colombiacompra.gov.co/.

Departamento Administrativo Nacional de Estadística. Disponible en línea https:// www.dane.gov.co/files/sen/bp/Codigo_nal_buenas_practicas.pdf. [Consultado el 16 de agosto de 2017].

Departamento de Planeación Nacional. Disponible en línea https:/www.dnp.gov. co/CONPES/Paginas/conpes.aspx. [Consultado el 16 de agosto de 2017].

Jurisprudencia Consejo de Estado y Corte Constitucional. http://www.consejodeestado.gov.co/y http://www.corteconstitucional.gov.co/.

Ministerio de Ambiente, Vivienda y Desarrollo Territorial. http://www.minambiente.gov.co/.

SuPERINTENDEnCia FinANCIERA. Disponible en línea https://www.superfinanciera.gov.co/ SFCant/Codigopais/textos/codigopias.pdf. [Consultado el 16 de agosto de 2017].

Unidad Administrativa Especial para la Atención y Reparación de las Víctimas. Disponible en línea http://escuela.unidadvictimas.gov.co/cartillas/Conpes_escuela.pdf. [Consultado el 16 de agosto de 2917]. 